\title{
Certify or not? An Analysis of Organic Food Supply Chain with Competing Suppliers
}

\author{
Yanan Yu' ${ }^{1}$, Yong $\mathrm{He}^{1, *}$, Xuan Zhao ${ }^{2}$, Li Zhou ${ }^{3}$ \\ ${ }^{1}$ School of Economics and Management, Southeast University, Nanjing, 210096, China \\ ${ }^{2}$ Lazaridis School of Business and Economics, Wilfrid Laurier University, Waterloo, ON \\ N2L 3C5, Canada \\ ${ }^{3}$ Business School, University of Greenwich, London, SE10 9LS, UK
}

\begin{abstract}
Customers expect companies to provide clear health-related information for the products they purchase in a big data environment. Organic food is data-enabled with the organic label, but the certification cost discourages the small-scale suppliers from certifying their product, which makes the product satisfying the organic standard regarded as conventional product. By considering the trade-off between the profit gained from organic label and additional certification cost, this paper investigates an organic food supply chain where a leading retailer procures from two suppliers with different brands. Customers care about both the brand-value and quality (more specifically, organic or not) when purchasing the product. We explore the organic certification and wholesale pricing strategies for suppliers, and the supplier selection and retail pricing strategies for the retailer. We find that when two suppliers adopt asymmetric certification strategy, the retailer tends to procure the product with organic label. The supplier without a brand name can compensate by organic certification, which can even obtain more profits than the rival. As the risk of being quitted by the retailer increases, the supplier without a brand name is more eager than the rival to obtain the organic label. However, two suppliers will fall into a prisoner's dilemma with low health utility from organic label and high certification cost if they both certify the product.
\end{abstract}

Keywords: Organic certification; Pricing; Competing suppliers; Food supply chain

\footnotetext{
${ }^{*}$ Corresponding author. E-mail address: hy@seu.edu.cn (Yong He)
} 


\section{Introduction}

According to Blueweave Consulting \& Research Pvt Ltd, the global organic food market is expected to grow at a CAGR over 15\% during 2018-2026 in terms of dollar value, and health is among one of the main factors inducing customers' organic food purchase intention ${ }^{1}$. Since globalization has brought many positive changes to developing countries (Cui and Song, 2019; Feng et al., 2019) and sustainable development (Cui and Huang, 2018), growth in organic farming in developing countries was mainly based on increasing exports of organic food to developed countries (Parrott et al., 2007). Many researchers show that health constitutes one of the principal purchasing motives for organic food (Bauer et al., 2013; Vega-Zamora et al., 2014; Popa et al., 2018; Sazvaret et al., 2018), particularly because of its wholesomeness and absence of chemicals (Schifferstein and Ophuis, 1998). Health-conscious customers are also more likely to consume organic food (Chen, 2007; DeMagistris and Gracia, 2008; Goetzke et al., 2014; Filippini et al., 2018).

The question of health is influenced by a lack of information, and the marketing strategies adopted by companies which bring about an increase in the information asymmetry between producers and customers (Marotta et al., 2014). Dabbert et al. (2014) think that the organic quality of a product is rooted in the production process rather than in any measurable quality of the product that could be experienced or directly observed before the product is purchased. Big data is emerging as an important information technology to guide decisions within agri-food supply chains (Ahearn et al., 2016), and big data applications in farming can alleviate food security concerns (Chen et al., 2014). Organic certification schemes require extensive product and process information, the traceability system related to big data is increasingly applied to evaluate the authenticity of organic product samples (Barbosa et al., 2014; Barbosa et al., 2016). Meanwhile, big data revolution reshapes the way customers and producers think about and make decisions regarding food purchases and production

\footnotetext{
${ }^{1}$ https://www.researchandmarkets.com/research/w9wn47/global_organic?w=5
} 
practices, and customers expect companies to provide clear, accurate and useful food-related information for the products they purchase (Pollard et al., 2019). Since the organic label acts as an indicator of healthfulness, a food with an organic label tends to be perceived as more healthful than the same food without such a label (Schifferstein and Ophuis, 1998; Lee et al., 2013; Ellison et al., 2016).

For producers who conduct organic practices, the decision to certify or not is based on their perception of the costs and benefits of organic certification. Barrett et al. (2002) point out that international certification and inspection can be very expensive for suppliers in developing countries. Veldstra et al. (2014) demonstrate that certification costs might discourage farmers from becoming certified. In their study, $71 \%$ of those who use any organic practices choose not to certify. Other research has shown that large farms tend to certify while small farms do not (Klonsky and Tourte, 1998). Snider et al. (2017) find that low customer demand, high auditing and certification costs, and weak financial incentives encourage cooperative to certify individual members rather than all members. Clark et al. (2016) also think that most agricultural certification initiatives are private initiatives that are costly for small-producers with limited access to capital. In China, many agricultural product suppliers sell wild and native produce which has satisfied the standards of organic certification, while they seldom choose to certify their product. However, farmers (implicitly) observing all organic requirements must obtain certification if they wish to sell their products as organic in relatively large, anonymous markets or in state supervised markets (Veldstra et al., 2014); otherwise, they may be considered as conventional products. Hazell et al. (2010) also point out that supermarkets have become dominant in the food market, but it is difficult for smallholders to meet the required standard of supermarkets. Therefore, it is critical for the food supplier to decide the certification strategy based on the trade-off between the benefits from certification (additional health utility from certification) and the cost of certification.

Retailers often sell multiple brands of a single type of product (Krishna, 1992; Baltas, 2004; Teng et al., 2007). According to Luo et al. (2016), most people prefer 
shopping in large malls, supermarkets, and big-box stores offering a variety of brands for many products rather than in direct-sale stores of particular brands. A similar phenomenon can be found in the food industry, and the importance of brands in affecting food consumption has been widely examined (e.g., Anselmsson et al., 2014; Sjostrom et al., 2014). Thus, the retailer will decide whether to procure products from multiple suppliers or one of them. Furthermore, the retailer should also set the retailing price for products according to the certification strategy of food suppliers. Since food industry faces intense competition, how should the food suppliers make their certification strategy under competition?

According to the research findings shown in the literature review, we find that competition may further weaken the benefits of certification (high certification cost is the basic barrier for small-scale producers). However, if one of competing suppliers chooses not to certify the product, his product is likely to be considered as conventional. What is worse, he will suffer the risk of quitting the market especially when the retailer may choose only one supplier. Thus, it is essential for suppliers to make certification strategy by taking the competition into consideration. We propose a modeling framework in which the retailer procures product from two suppliers: supplier 1 with a brand name and supplier 2 without a brand name. We consider two products competing on two attributes, one is brand value, the other is health utility which has been defined as the influence that customers believe consuming organic product has on their health (Howlett et al., 2009).

This paper attempts to enhance the discussion on organic certification considering those whose actual organic practices already satisfy the certification standard. Past studies have indicated that organic food is perceived healthier than conventionally produced food for both environment and human (Michaelidou and Hassan, 2008). Health is among main factors inducing customers' organic food purchase intention (Hsu et al., 2016). If one supplier chooses not to certify, the product will be considered as conventional and lose health utility, if the supplier chooses to certificate the product, the product will obtain additional health utility by 
confirming that the process of producing does not use pesticides, growth hormones or antibiotics, but the supplier must pay the certification cost. We incorporate a customer choice model to determine demand, we assume that customers value product 1 higher than product 2 in terms of brand, but that the difference between the valuations of the two types of products varies across individuals. In addition, we use health utility to capture the difference between the products with and without organic label. Due to the equivalence of organic standards, we assume that customers obtain the same health utility from organic label which is independent of the brand of the product. We find that supplier 2 with low brand recognition sometimes can improve the deficiency in brand by organic certification, and he is more eager to adopt certification strategy with higher risk of being quitted by the retailer. When the suppliers simultaneously certify the product, they may fall into the prisoner's dilemma with higher certification cost and lower health utility from organic label.

This paper contributes to the literature in several ways. First, our study combines two utilities, namely, brand value and health utility, they both affect the customer's surplus in purchasing the food, which further segments the market by means of the customer's surplus in purchasing each product. Second, we clearly identify the conditions under which the suppliers should certificate the product. Third, we conclude the conditions when the retailer should procure the product from both brands or a single brand, and decide the corresponding pricing strategies of the retailer and the suppliers. Our research aims to address the following key questions:

(1) Under what conditions will the suppliers certificate the product? Will organic certification always benefit the suppliers?

(2) What is the optimal supplier selection strategy for the retailer?

(3) What are the impacts of health utility from certification and customers' brand recognition on the optimal pricing policies, profits of the retailer and the suppliers, and on the strategy of the certification considering certification cost?

The rest of this paper is organized as follows. Section 2 discusses the related literature. In Section 3, the model formulation and assumptions are presented, and the 
customer demand is obtained according to the customers' utility functions. Section 4 studies two suppliers' and the retailer's pricing decisions under different certification scenarios, and provides Nash equilibrium certification strategy when competing suppliers simultaneously make decisions. Section 5 concludes our research findings and points out further extensions of this work.

\section{Literature review}

First, our work is closely related to studies of the organic certification strategy under competition. Clark et al. (2016) conclude that access to certification may not be effective if it is not accompanied by other measures and policies favorable to small-scale producers. Beuchelt and Zeller (2011) show that organic and organic-fairtrade farmers have become poorer relative to conventional producers. Some researchers consider that when labelling products from different countries use the same organic logo, it will reduce customers' differentiation between organic products from different countries if customers are informed about the equivalence of organic standards (Janssen and Hamm, 2012b; Xie et al., 2016). However, researchers mainly study the certification strategy through empirical research, there are very limited studies that study the strategy of organic certification from the perspective of operations management.

Our work is also related to the studies on pricing decisions based on quality under competition. Some researchers study the model with two competing retailers or manufacturers, Motta (1993) develops a pricing strategy based on quality and the customer taste in a Bertrand duopoly model. Karaer and Erhun (2015) analyze the role of quality as a competitive tool in a price and quality-based setting. Jing (2016) examines how behavior-based price discrimination affects the firms' endogenous quality differentiation and profits. Ozinci et al. (2017) consider pricing decisions of agri-food retailers offering organic food and conventional food, where the two product versions differ from each other in terms of their shelf lives and their utility to customers. Zhou (2018) examines the role of green consumerism under competition by incorporating product types and customer groups, and shows that the existence of 
green customers is beneficial to the green manufacturer and two groups of customers. Wu et al. (2018) study the sampling and pricing strategies for sellers of competing products in an oligopoly market, and they show that the intensity of product competition and customer switching behavior play important roles in determining equilibrium sampling strategy. Our research is similar to theirs, we extend the model to the two-stage supply chain, and study the retailer's supplier selection strategy. They study the sampling and pricing strategies considering horizontal product differentiation by using a Hotelling model, while our model considers vertical product differentiation.

Some researchers also study the pricing decisions based on quality under competition in a two-stage supply chain. Matsubayashi (2007) studies the problem that two firms compete in determining their prices and quality levels to maximize their profits, and shows that differentiation always increases the firms' profits, but also it can increase the customers' welfare in a quality-sensitive market. Matsubayashi and Yamada (2008) further study the impact of asymmetric customer loyalty on two firms' competition under a setting where the firms simultaneously determine their prices and quality levels. Wang et al. (2017) explore the interaction of channel structure with price and quality-based competition between two manufacturers who are asymmetric on customer loyalty. They divide the market into the price-sensitive market and quality-sensitive market, and find that the equilibrium depends on the market type. Luo et al. (2017) investigate a supply chain consisting of two manufacturers with a good brand and an average brand, and study the optimal pricing policies for differentiated brands under different supply chain power structures.

In terms of pricing decisions in a non-perishable agricultural supply chain, Assefa et al. (2014) develop a classic oligopoly model to assess the degree of price transmission in a two-stage farmer-retailer supply chain. Perlman et al. (2019) study the pricing decisions in a dual supply chain where organic and conventional suppliers simultaneously distribute their product directly to customers and via a single retailer who sells both product versions. Others focus on the pricing of fresh produce in a 
supply chain, they mainly consider the deterioration of the product, and study the pricing decision and coordination (Blackburn and Scudder, 2009; Cai et al., 2010; Cai et al., 2013; Wang and Chen, 2017).

However, most of the studies considering organic certification strategy are from the perspective of empirical study. A few above-mentioned studies (see e.g., Luo et al., 2017) focus on supplier selection under competition. A few other studies (see e.g., Wu et al., 2018) have considered the decision of quality information revealing under competition. Here, we combine the problems of supplier selection and quality information disclosure, trying to solve the certification strategy under competition. Table 1 makes a summary of relevant literature.

Table 1. Summary of relevant literature.

\begin{tabular}{|c|c|c|c|c|c|}
\hline Authors(s) & $\begin{array}{l}\text { Pricing } \\
\text { strategy }\end{array}$ & $\begin{array}{c}\text { Certification } \\
\text { strategy }\end{array}$ & $\begin{array}{c}\text { Supply } \\
\text { chain }\end{array}$ & Competition & $\begin{array}{c}\text { Agricultural } \\
\text { product }\end{array}$ \\
\hline Motta (1993) & $\sqrt{ }$ & & & $\sqrt{ }$ & \\
\hline Matsubayashi (2007) & $\sqrt{ }$ & & $\sqrt{ }$ & $\sqrt{ }$ & \\
\hline Matsubayashi and Yamada (2008) & $\sqrt{ }$ & & $\sqrt{ }$ & $\sqrt{ }$ & \\
\hline Blackburn and Scudder (2009) & $\sqrt{ }$ & & $\sqrt{ }$ & & $\sqrt{ }$ \\
\hline Cai et al. (2010) & $\sqrt{ }$ & & $\sqrt{ }$ & & $\sqrt{ }$ \\
\hline Beuchelt and Zeller (2011) & & $\sqrt{ }$ & & $\sqrt{ }$ & $\sqrt{ }$ \\
\hline Janssen and Hamm (2012b) & & $\sqrt{ }$ & & $\sqrt{ }$ & $\sqrt{ }$ \\
\hline Cai et al. (2013) & $\sqrt{ }$ & & $\sqrt{ }$ & & $\sqrt{ }$ \\
\hline Assefa et al. (2014) & $\sqrt{ }$ & & $\sqrt{ }$ & $\sqrt{ }$ & $\sqrt{ }$ \\
\hline Karaer and Erhun (2015) & $\sqrt{ }$ & & & $\sqrt{ }$ & \\
\hline Clark et al. (2016) & & $\sqrt{ }$ & & $\sqrt{ }$ & $\sqrt{ }$ \\
\hline Jing (2016) & $\sqrt{ }$ & & & $\sqrt{ }$ & \\
\hline Xie et al. (2016) & & $\sqrt{ }$ & & $\sqrt{ }$ & $\sqrt{ }$ \\
\hline Luo et al. (2017) & $\sqrt{ }$ & & $\sqrt{ }$ & $\sqrt{ }$ & \\
\hline Ozinci et al. (2017) & $\sqrt{ }$ & & & $\sqrt{ }$ & $\sqrt{ }$ \\
\hline Wang et al. (2017) & $\sqrt{ }$ & & $\sqrt{ }$ & $\sqrt{ }$ & \\
\hline Wang and Chen (2017) & $\sqrt{ }$ & & $\sqrt{ }$ & & $\sqrt{ }$ \\
\hline Wu et al. (2018) & $\sqrt{ }$ & & & $\sqrt{ }$ & \\
\hline Zhou (2018) & $\sqrt{ }$ & & & $\sqrt{ }$ & \\
\hline Perlman et al. (2019) & $\sqrt{ }$ & & $\sqrt{ }$ & $\sqrt{ }$ & $\sqrt{ }$ \\
\hline This paper & $\sqrt{ }$ & $\sqrt{ }$ & $\sqrt{ }$ & $\sqrt{ }$ & $\sqrt{ }$ \\
\hline
\end{tabular}

\section{Model setting}

We consider two competing suppliers producing one type of agricultural product 
which follows the organic practice, denoted by $s_{1}$ and $s_{2}$, to a retailer. The retailer is the leader who plays a dominant role in this supply chain. Retailers, such as Wal-Mart and Carrefour (Ertek\& Griffin, 2002), may play a more dominant role than upstream members. Two suppliers have balanced power and make decisions simultaneously. Customers are heterogeneous in the valuation of the product, big Data opens a wide range of possibilities for organizations to understand the needs of their customers, predict their preference and shopping patterns, and optimize the use of resources (Assunção et al., 2015), which contributes to market segmentation by understanding customer behavior. We assume customers value the brand name of supplier 1 at $v$ which is uniformly distributed on [0,1] (Chiang et al., 2003), and value the no-name product of supplier 2 at $\theta v$, where $\theta$ means customer acceptance for the no-name product and $\theta \in(0,1)$ (Luo et al., 2017), $\theta$ can also reflect the competition intensity, and a larger $\theta$ means a stronger competition intensity. For instance, the Chinese people view rice from Harbin higher than other rice, scientists have developed different brands that are tailored for each specific region based on the ecological environment in different regions of Harbin, especially, Wuchang in Harbin is famous for the brand Daohuaxiang (see http://www.chinadaily.com.cn/regional/Harbinrice.html). The brand competition intensity of rice in Harbin is high, however, that between Harbin and other cities in China is low. Since this paper considers two suppliers with different brands, thus, $\theta \neq 1$. If $\theta=1$, two suppliers show no difference in terms of brand recognition, the certification equilibrium will be symmetric (Proof see Appendix A2). If the supplier spends cost $F$ certifying the product, he can obtain the organic label to confirm the product being organic; otherwise, the product will be considered as conventional. We assume customers are concerned about healthy eating, they will obtain additional utility from purchasing organic products which can be denoted as $\Delta$ and $\Delta \in(0,1]$. The retailer sets the marginal profit for two products which can be denoted as $m_{n}(n=1,2)$. Supplier's wholesale price is $w_{n}$, and the selling price is $p_{n}$ which satisfies $p_{n}=m_{n}+w_{n}$. Fig.1 illustrates the sequence of the game. In stage 1 , two 
suppliers simultaneously determine whether to certify the product or not. In stage 2, the retailer chooses to procure products from either both suppliers or one of them considering the suppliers' certification decisions and anticipating the wholesale prices of two products, and determines the corresponding marginal profit per unit. In stage 3, given the marginal profit for the two products, the suppliers simultaneously decide the wholesale prices. In stage 4, the customers decide to purchase the product with a good brand (with brand name) or an average brand (no name) according to their net utilities.

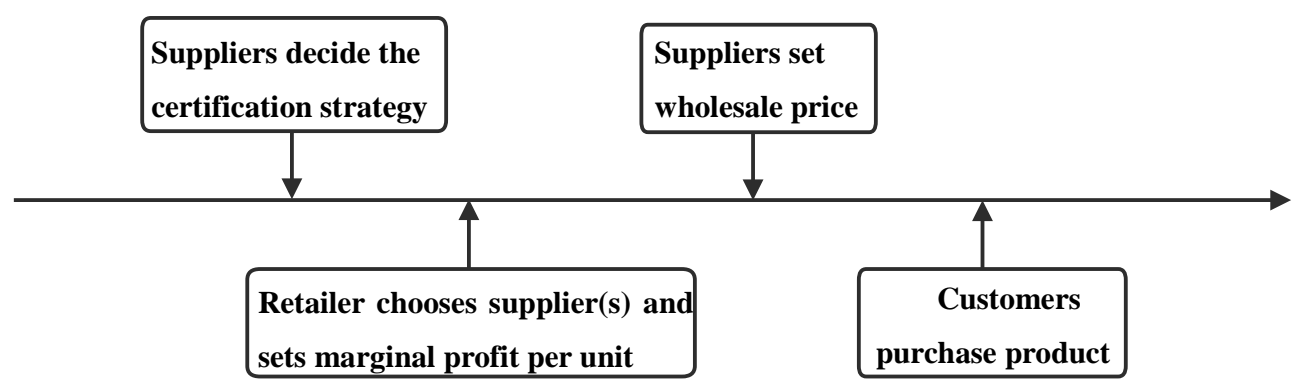

Fig. 1. The sequence of events in the game.

Let $\zeta_{n}$ be the indicator function characterizing the certification decision, that is,

$$
\zeta_{n}(n=1,2)=\left\{\begin{array}{l}
1, \quad \text { certification, } \\
0, \quad \text { no certification. }
\end{array}\right.
$$

Let $u_{1}=v-p_{1}+\zeta_{1} \Delta$ be the utility a customer derives from product 1 , and $u_{2}=$ $\theta v-p_{2}+\zeta_{2} \Delta$ is the utility a customer derives from product 2. The customer will choose to buy the product from supplier 1 only if $v-p_{1}+\zeta_{1} \Delta \geq \theta v-p_{2}+\zeta_{2} \Delta$ and $v-p_{1}+\zeta_{1} \Delta \geq 0$. When $v-p_{1}+\zeta_{1} \Delta<\theta v-p_{2}+\zeta_{2} \Delta$ and $\theta v-p_{2}+\zeta_{2} \Delta \geq 0$, the customer will buy the product from supplier 2. Thus, the demand function can be modeled as follows.

$$
\begin{gathered}
D_{1}=\left\{\begin{array}{cc}
1-p_{1}+\zeta_{1} \Delta, & 0<\theta<\frac{p_{2}-\zeta_{2} \Delta}{p_{1}-\zeta_{1} \Delta} \\
1-\frac{p_{1}-p_{2}+\left(\zeta_{2}-\zeta_{1}\right) \Delta}{1-\theta}, & \frac{p_{2}-\zeta_{2} \Delta}{p_{1}-\zeta_{1} \Delta} \leq \theta \leq 1-p_{1}+p_{2}+\left(\zeta_{1}-\zeta_{2}\right) \Delta, \\
0, & 1-p_{1}+p_{2}+\left(\zeta_{1}-\zeta_{2}\right) \Delta<\theta<1
\end{array}\right. \\
D_{2}=\left\{\begin{array}{cc}
0, & 0<\theta<\frac{p_{2}-\zeta_{2} \Delta}{p_{1}-\zeta_{1} \Delta} \\
\frac{p_{1}-p_{2}+\left(\zeta_{2}-\zeta_{1}\right) \Delta}{1-\theta}-\frac{p_{2}-\zeta_{2} \Delta}{\theta}, & \frac{p_{2}-\zeta_{2} \Delta}{p_{1}-\zeta_{1} \Delta} \leq \theta \leq 1-p_{1}+p_{2}+\left(\zeta_{1}-\zeta_{2}\right) \Delta . \\
1-\frac{p_{2}-\zeta_{2} \Delta}{\theta}, & 1-p_{1}+p_{2}+\left(\zeta_{1}-\zeta_{2}\right) \Delta<\theta<1
\end{array}\right.
\end{gathered}
$$


Let subscripts $s$ and $r$ represent the suppliers and the retailer, respectively. The suppliers’ profit functions are:

$$
\begin{aligned}
& \pi_{s 1}=\left(w_{1}-c_{1}\right) D_{1}-\zeta_{1} F, \\
& \pi_{s 2}=\left(w_{2}-c_{2}\right) D_{2}-\zeta_{2} F .
\end{aligned}
$$

The retailer's profit function is:

$$
\pi_{r}=m_{1} D_{1}+m_{2} D_{2} .
$$

The market size of potential customers is normalized to 1 and the production costs of the suppliers are normalized to zero without loss of generality, we further study the model considering production costs in Appendix D. Each customer purchases at most 1 unit product.

\section{Equilibrium certification strategy}

Backward induction is used to solve this leader-follower game. Since two suppliers are the followers in terms of pricing, first, the suppliers assume the retailer's marginal profit is known and obtain their optimal response function to maximize the profit. Then, with the suppliers' response function known, the retailer solves the profit maximization problem and optimizes the marginal profit. After solving the suppliers' and the retailer's pricing strategy under four different certification scenarios, we finally solve the suppliers' certification strategy and the retailer's supplier selection strategy. However, since the suppliers' certification strategy which has a great effect on retailer's decision prior to retailer's supplier selection strategy, we will solve retailer's supplier selection strategy firstly, then determine suppliers' certification decisions by using backward induction.

From the proof shown in Appendix A1, we obtain the basic solutions as follows. When $0<\theta<\frac{p_{2}-\zeta_{2} \Delta}{p_{1}-\zeta_{1} \Delta}$, the retailer only procures products from supplier 1 , the marginal profit, wholesale price, selling price of product 1 , and profits for supplier 1 and the retailer are:

$$
\begin{aligned}
& m_{1}^{*}=\frac{1+\zeta_{1} \Delta}{2}, \\
& w_{1}^{*}=\frac{1+\zeta_{1} \Delta}{4},
\end{aligned}
$$




$$
\begin{gathered}
p_{1}^{*}=\frac{3\left(1+\zeta_{1} \Delta\right)}{4}, \\
\pi_{s 1}^{*}=\frac{\left(1+\zeta_{1} \Delta\right)^{2}}{16}-\zeta_{1} F, \\
\pi_{r}^{*}=\frac{\left(1+\zeta_{1} \Delta\right)^{2}}{8} .
\end{gathered}
$$

When $\frac{p_{2}-\zeta_{2} \Delta}{p_{1}-\zeta_{1} \Delta} \leq \theta \leq 1-p_{1}+p_{2}+\left(\zeta_{1}-\zeta_{2}\right) \Delta$, the retailer procures both products from supplier 1 and supplier 2. The marginal profits, wholesale prices, selling prices of two products and profits for suppliers and the retailer are:

$$
\begin{gathered}
m_{1}^{*}=\frac{1+\zeta_{1} \Delta}{2}, \\
m_{2}^{*}=\frac{1}{2}\left(\theta+\zeta_{2} \Delta\right), \\
w_{1}^{*}=\frac{2-2 \theta+(2-\theta) \zeta_{1} \Delta-\zeta_{2} \Delta}{2(4-\theta)}, \\
w_{2}^{*}=\frac{\theta\left(1-\theta-\zeta_{1} \Delta\right)+(2-\theta) \zeta_{2} \Delta}{2(4-\theta)}, \\
p_{1}^{*}=\frac{6-3 \theta+2(3-\theta) \zeta_{1} \Delta-\zeta_{2} \Delta}{2(4-\theta)}, \\
p_{2}^{*}=\frac{\theta\left(5-2 \theta-\zeta_{1} \Delta\right)+2(3-\theta) \zeta_{2} \Delta}{2(4-\theta)}, \\
\pi_{s 1}^{*}=\frac{\left(2-2 \theta+(2-\theta) \zeta_{1} \Delta-\zeta_{2} \Delta\right)^{2}}{4(4-\theta)^{2}(1-\theta)}-\zeta_{1} F, \\
\pi_{s 2}^{*}=\frac{\left(\theta\left(1-\theta-\zeta_{1} \Delta\right)+(2-\theta) \zeta_{2} \Delta\right)^{2}}{4(4-\theta)^{2}(1-\theta) \theta}-\zeta_{2} F, \\
\pi_{r}^{*}=\frac{\theta\left(2-\theta-\theta^{2}\right)+\theta \zeta_{1} \Delta\left(4(1-\theta)+(2-\theta) \zeta_{1} \Delta\right)+2 \theta\left(1-\theta-\zeta_{1} \Delta\right) \zeta_{2} \Delta+(2-\theta) \zeta_{2}{ }^{2} \Delta^{2}}{4(4-\theta)(1-\theta) \theta} .
\end{gathered}
$$

When $1-p_{1}+p_{2}+\left(\zeta_{1}-\zeta_{2}\right) \Delta<\theta<1$, the retailer only procures products from supplier 2, the marginal profit, wholesale price, selling price of product 2, and profits for supplier 2 and the retailer are:

$$
\begin{gathered}
m_{2}^{*}=\frac{1}{2}\left(\theta+\zeta_{2} \Delta\right), \\
w_{2}^{*}=\frac{1}{4}\left(\theta+\zeta_{2} \Delta\right), \\
p_{2}^{*}=\frac{3}{4}\left(\theta+\zeta_{2} \Delta\right), \\
\pi_{s 2}^{*}=\frac{\left(\theta+\zeta_{2} \Delta\right)^{2}}{16 \theta}-\zeta_{2} F, \\
\pi_{r}^{*}=\frac{\left(\theta+\zeta_{2} \Delta\right)^{2}}{8 \theta} .
\end{gathered}
$$




\subsection{Equilibrium pricing decisions for given certification scenarios}

For the suppliers, there are four certification scenarios: (I) both suppliers implement the certification activity (certification-certification strategy), (II) certification-no certification strategy, (III) no certification-certification strategy, and (IV) neither of suppliers implements the certification activity (no certification-no certification strategy).

Lemma 1. When the retailer simultaneously procures products from two suppliers,

(i) In four certification scenarios, supplier 1's wholesale price and profit always decrease in $\theta$;

(ii) In four certification scenarios, when $\Delta>\frac{4-8 \theta+\theta^{2}}{4 \zeta_{1}+2 \zeta_{2}}$, supplier 2's wholesale price decreases in $\theta$; otherwise, it is unimodal in $\theta$, that is, supplier 2's wholesale price increases in $\theta$ when $\theta<4-2 \sqrt{3}$ and decreases in $\theta$ when $\theta>4-2 \sqrt{3}$;

(iii) In scenario I and scenario II, when $\theta>\frac{4}{7}$, supplier 2 's profit decreases in $\theta$; otherwise, it increases in $\theta$ when $\Delta<\frac{(1-\theta) \theta(-4+7 \theta)}{\theta(-4+\theta(-1+2 \theta))+(-8+\theta(18+\theta(-9+2 \theta))) \zeta_{2}}$ and decreases in $\theta$ when $\Delta>\frac{(1-\theta) \theta(-4+7 \theta)}{\theta(-4+\theta(-1+2 \theta))+(-8+\theta(18+\theta(-9+2 \theta))) \zeta_{2}}$;

(iv) In scenario III, when $\frac{4}{7}<\theta<\frac{9-\sqrt{17}}{8}$, supplier 2's profit decreases in $\theta$; when $\theta>\frac{9-\sqrt{17}}{8}$, supplier 2's profit firstly decreases in $\theta$ if $\Delta<\frac{(1-\theta) \theta(-4+7 \theta)}{-8+\theta(18+\theta(-9+2 \theta))}$ and then increases in $\theta$; when $\theta<\frac{4}{7}$, supplier 2's profit firstly increases in $\theta$ if $\Delta<$ $\frac{(1-\theta) \theta(-4+7 \theta)}{-8+\theta(18+\theta(-9+2 \theta))}$ and then decreases in $\theta$. In scenario IV, it increases in $\theta$ when $\theta<\frac{4}{7}$ and decreases in $\theta$ when $\theta>\frac{4}{7}$

One may intuitively think that supplier 2's wholesale price will always increase in $\theta$. Lemma 1(ii) shows that this intuition is correct when both the health utility brought by organic certification and supplier 2's brand recognition are low. However, once one of the above two factors is high, this intuition may not be true. In scenario I, $D_{1}^{*}-D_{2}^{*}=$ $\frac{\Delta(-2+\theta)+\theta}{2(4-\theta) \theta}$, keeping $\Delta$ fixed, if $\theta>\frac{2 \Delta}{1+\Delta}$, the demand for product 1 will exceed that of 
product 2. Supplier 2 will lower the wholesale price to motivate the retailer to procure product 2, which makes supplier 2's profit decrease in $\theta$ when $\theta>\frac{4}{7}$. However, supplier 2 can still reduce the profit gap between two products with the increase of $\theta$ since supplier 1's profit also decreases in $\theta$. Supplier 2 can lower the selling price gap between two products by certification (i.e., $\frac{\partial p_{1}^{*}-p_{2}^{*}}{\partial \Delta}<0$ ). The selling price of product 2 always increases in $\theta$ and $\Delta$, since low health utility leads to product 2's low selling price, the decline in demand caused by the rise in selling price due to the increase of $\theta$ is weak. However, higher health utility leads to higher decline in demand. Supplier 2 will lower the wholesale price to boost demand with an increase of $\theta$.

In scenario II, the wholesale price and profit of product 2 will increase in $\theta$ when both brand recognition and health utility are low. Since $D_{2}=\frac{p_{1}-p_{2}-\Delta}{1-\theta}-\frac{p_{2}}{\theta}$, we find that when $\Delta$ is high, supplier 1's certification behavior will heavily weaken supplier 2's demand, such inferiority increases as $\theta$ increases (i.e., $\frac{\partial^{2} D_{2}}{\partial \Delta \partial \theta}<0$ ), thus, supplier 2 will reduce the wholesale price when $\theta$ is high, which also hurts his profit.

In scenario III, we find that when only supplier 2 certificates the product, supplier 2's profit increases in $\theta$ only if health utility and brand recognition are both low or high. When health utility is low, supplier 2 has to reduce his wholesale price with a high brand recognition, which weakens supplier 2's profit. We find that $\frac{\partial p_{2}^{*}}{\partial \Delta}=\frac{3-\theta}{4-\theta}>0$ and $\frac{\partial^{2} p_{2}^{*}}{\partial \Delta \partial \theta}<0$, which means that when $\theta$ is high, the increase of selling price due to higher health utility is weak, thus, supplier 2 can still raise his wholesale price. However, accompanied by supplier 2's low brand recognition and high health utility, the increase of selling price due to higher health utility is rapid, which will reduce the customer demand for product 2, supplier 2 will lower wholesale price to boost demand. Therefore, supplier 2's profit will decrease in $\theta$ with a low brand recognition and high health utility.

In scenario IV, the retailer will always set a margin profit increasing in supplier 2's brand recognition for product 2. When $\theta$ is low, supplier 2 still raises his wholesale 
price as $\theta$ increases, which is beneficial for his profit. However, the corresponding selling price will be gradually higher with the increase of $\theta$. When $\theta$ is high, the margin profit for product 2 still keeps increasing, supplier 2 has to reduce his wholesale price to avoid demand loss brought by a rapidly-growing selling price. Thus, the profit of supplier 2 will decrease in $\theta$ when $\theta>\frac{4}{7}$.

Define the profit of entire supply chain as $\pi_{s C}=\pi_{r}+\pi_{s 1}+\pi_{s 2}$, and the customer surplus can be denoted as $E(C S)=E\left(\int_{\frac{p_{1}-p_{2}+\left(\zeta_{2}-\zeta_{1}\right) \Delta}{1-\theta}}^{1} v-p_{1}+\zeta_{1} \Delta d v+\right.$ $\left.\int_{\frac{p_{2}-\zeta_{2} \Delta}{\theta}}^{\frac{p_{1}-p_{2}+\left(\zeta_{2}-\zeta_{1}\right) \Delta}{1-\theta}} \theta v-p_{2}+\zeta_{2} \Delta d v\right)$, then, we have the following findings.

Proposition 1. When two suppliers simultaneously certify the product:

(i) If $\theta>\frac{2}{13}(3 \sqrt{3}-1)$, the retailer's profit increases in $\theta$; otherwise, it increases in $\theta$ if $\Delta<\Delta_{r}^{*}$ and decreases in $\theta$ if $\Delta>\Delta_{r}^{*}$;

(ii) The profit of the supply chain increases in $\theta$ if $\Delta<\Delta_{S c}^{*}$ and decreases in $\theta$ if $\Delta>\Delta_{S C}^{*}$

(iii) If $\theta>\theta_{c S}^{*}$, the customer surplus increases in $\theta$; otherwise, it increases in $\theta$ if $\Delta<\Delta_{c S}^{*}$ and decreases in $\theta$ if $\Delta>\Delta_{C S}^{*}$;

where $\quad \Delta_{r}^{*}=\frac{6}{-3+\sqrt{3}(4-\theta)} \quad, \quad \Delta_{S c}^{*}=\frac{(4-7 \theta) \theta^{2}+\theta(4-\theta) \sqrt{60+3 \theta(-22+5 \theta)}}{2(24+\theta(-18+\theta(5+\theta)))} \quad, \quad \Delta_{c S}^{*}=$ $\frac{\theta^{2}(20+\theta)+\theta(4-\theta) \sqrt{(28-(2-\theta) \theta)}}{2(2+\theta)(4-5 \theta)}$.

We learn from Proposition 1(i) and Proposition 1(iii) that both the retailer and customers can benefit from supplier 2's high brand recognition. If two suppliers simultaneously certify the product, they show no differences in terms of health utility. When $\theta$ is high, two suppliers compete head-to-head, none of them can charge a high price, which attracts more customers. Therefore, the retailer will benefit from higher demand, and the customer surplus will be improved. However, if customers obtain relatively high health utility from the organic label, two suppliers can still set a high wholesale price to obtain more profits. Therefore, the customer surplus does not 
always increase in $\theta$, the retailer's profit and the customer surplus will decrease in $\theta$ with low competition intensity and high health utility from organic label.

Proposition 2. When two suppliers simultaneously certify the product, the profit gap between two suppliers decreases in $\Delta$, compared with the scenario that they both do not certify the product, the increase of profit decreases in $\theta$.

When two suppliers simultaneously certify the product, if we do not optimize the selling price, we get $D_{1}=1-\frac{p_{1}-p_{2}}{1-\theta}, D_{2}=\frac{p_{1}-p_{2}}{1-\theta}-\frac{p_{2}-\Delta}{\theta}$, the health utility brought from certification will be offset in the demand function of product 1 , while supplier 2 can obtain more demand due to certification. After we solve the optimal price, we find that $\frac{\partial p_{1}^{*}-p_{2}^{*}}{\partial \Delta}=\frac{-(1-\theta)}{2(4-\theta)}<0, \frac{\partial D_{1}^{*}-D_{2}^{*}}{\partial \Delta}=\frac{-(2-\theta)}{2(4-\theta) \theta}<0, \frac{\partial w_{1}^{*}-w_{2}^{*}}{\partial \Delta}=\frac{-(1-\theta)}{2(4-\theta)}<0$, especially, the demand of product 2 even exceeds that of product 1 when $\Delta>\frac{\theta}{2-\theta}$. Thus, the profit gap between two suppliers decreases in $\Delta$ due to the gap of both the demand and the wholesale price between two suppliers decreasing in $\Delta$. Keeping $\Delta$ fixed, competition intensity between two suppliers will be stronger as $\theta$ increases, which makes the increase of profit brought by certification decrease in $\theta$, that is, stronger competition intensity will weaken the benefits from organic certification.

\subsection{Supplier selection strategy for the retailer}

Proposition 3. When two suppliers adopt asymmetric certification strategies, the retailer tends to procure the product with organic label, especially when the health utility brought by organic certification becomes higher.

If we do not consider the production cost, we confirm that when two suppliers take symmetric strategies, the retailer will simultaneously procure products from two suppliers. When two suppliers take certification-no certification strategy, the retailer will procure two products simultaneously if $\Delta \leq 1-\theta$; otherwise, he will only procure products from supplier 1. When two suppliers take no certification-certification strategy, the retailer will procure two products simultaneously if $\Delta \leq 2-2 \theta$; otherwise, he will only procure products from supplier 
2. When the suppliers take asymmetric certification strategy, with a higher health utility brought from organic label, the wholesale price and supplier's profit of the one with certification increase, the selling price and profit of the retailer also increase, thus, the retailer is willing to procure the product with organic label. The wholesale price, selling price and supplier's profit of the one without certification decrease, and can even be quitted by the retailer.

\subsection{Equilibrium certification strategy for the suppliers}

According to the suppliers' pay-offs obtained from different certification scenarios and the retailer's supplier selection strategy, we then examine two suppliers' equilibrium certification strategy. When $\Delta \leq 1-\theta$, the retailer will simultaneously procure products from two suppliers regardless of suppliers' certification behavior. We have the final certification strategy as shown in Table 2.

Table 2. The organic certification strategy when $\Delta \leq 1-\theta$.

\begin{tabular}{|c|c|c|}
\hline$\theta$ & $\Delta$ & Case \\
\hline \multirow{3}{*}{$\theta<\frac{7-\sqrt{41}}{2}$} & $\Delta<\Delta_{11}$ & $(1)$ \\
\cline { 2 - 3 } & $\Delta_{11}<\Delta<\Delta_{12}$ & $(2)$ \\
\cline { 2 - 3 } & $\Delta_{12}<\Delta<\Delta_{13}$ & $(3)$ \\
\cline { 2 - 3 }$\frac{7-\sqrt{41}}{2}<\theta<\frac{5-\sqrt{17}}{2}$ & $\Delta<\Delta_{13}$ & $(4)$ \\
\cline { 2 - 3 } & $\Delta_{11}<\Delta<\Delta_{11}$ & $(1)$ \\
\cline { 2 - 3 } & $\Delta>\Delta_{12}$ & $(2)$ \\
\hline \multirow{2}{*}{$\theta>\frac{5-\sqrt{17}}{2}$} & $\Delta<\Delta_{11}$ & $(1)$ \\
\cline { 2 - 3 } & $\Delta>\Delta_{11}$ & $(2)$ \\
\hline
\end{tabular}

The equilibrium certification strategy can be seen in Appendix C.

From Table 2, we find that in each case, two suppliers adopt certification-certification strategy when $F$ is very low, and finally adopt no certification-no certification strategy when $F$ is very high. However, when $F$ is moderate, the certification strategy varies with the change of $\Delta$ and $\theta$. When the health utility brought from organic label is low $\left(\Delta<\Delta_{11}\right)$, if $\bar{F}_{11}<F \leq \bar{F}_{12}$, supplier 2 will decide whether to certify the product or not based on supplier 1's behavior and adopt the strategy contrary to supplier 1 . Low health utility discourages supplier 2 
from certificating the product. However, we have shown that low health utility will be more beneficial for supplier 1 in Proposition 2, thus, certification is supplier 1's dominant strategy, which makes supplier 2 adopt contrary strategy- no certification.

When health utility brought from organic label is high and $\theta$ is low $\left(\Delta>\Delta_{12} \cap\right.$ $\theta<\frac{5-\sqrt{17}}{2}$ ), if $\bar{F}_{13}<F \leq \bar{F}_{11}$ or $\bar{F}_{13}<F \leq \bar{F}_{14}$, since supplier 2's brand recognition is low, supplier 1 has no incentive to certificate the product. Furthermore, we have confirmed that if two suppliers certificate the product simultaneously, the profit gap between two suppliers will decrease with the increase of $\Delta$. Therefore, when $\Delta$ is high and $\theta$ is low, supplier 1 has no incentive to certificate the product, he will adopt the strategy contrary to supplier 2. However, supplier 2 can alleviate his deficiency in brand recognition by certification if $\Delta$ is high, thus, certification is supplier 2's dominant strategy, which makes supplier 1 adopt contrary strategy-no certification. However, Case (3) and Case (4) also differ with the increase of certification cost. When $\Delta>\Delta_{13}$ and in the region of $\bar{F}_{14}<F \leq \bar{F}_{11}$, both suppliers have dominant strategy in Case (4). For supplier 1, there is no need to certificate the product due to high health utility and supplier 2's low brand recognition, furthermore, the certification cost here is higher compared with the region of $\bar{F}_{13}<F \leq \bar{F}_{14}$, therefore, no certification will be supplier 1's dominant strategy. For supplier 2, since higher health utility will make up for the deficiency of low brand recognition, certification is still his dominant strategy if $\bar{F}_{14}<F \leq \bar{F}_{11}$, while certification will no longer be dominant with the increase of certification cost in the region of $\bar{F}_{11}<F \leq \bar{F}_{12}$. In Case (3), when $\bar{F}_{11}<F \leq \bar{F}_{14}$, none of the two suppliers have dominant strategy.

When $\theta$ is high $\left(\theta>\frac{5-\sqrt{17}}{2}\right)$, supplier 1 will realize the competitive threat from supplier 2, since supplier 1's brand recognition is higher than that of supplier 2, supplier 1 has more economic power in certificating the product. If $\bar{F}_{11}<F \leq \bar{F}_{12}$ in Case (1) or $\bar{F}_{11}<F \leq \bar{F}_{13}$ in Case (2), certification is supplier 1's dominant strategy. However, Case (1) and Case (2) also differ with the increase of certification cost. In Case (2), when $\Delta>\Delta_{11}$ and in the region of $\bar{F}_{13}<F \leq \bar{F}_{12}$, since supplier 2's brand recognition and health utility from organic label are both high, both of two 
suppliers have no dominant strategy. For supplier 1, higher health utility from organic label is not too beneficial, although supplier 2 has a relatively high brand recognition, the certification cost is higher compared with the region $\bar{F}_{11}<F \leq \bar{F}_{13}$, thus, the certification strategy is no longer supplier 1's dominant strategy. For supplier 2, since higher health utility will be more beneficial for him, no certification is not his dominant strategy either. In Case (1), when $\Delta<\Delta_{11}$ and in the region of $\bar{F}_{12}<F \leq$ $\bar{F}_{13}$, both of two suppliers have dominant strategy. For supplier 1, facing supplier 2's high brand recognition and low health utility, certification is still supplier 1's dominant strategy. For supplier 2, the certification cost is higher compared with the region $\bar{F}_{11}<F \leq \bar{F}_{12}$, and health utility is low here, thus, no certification is supplier 2's dominant strategy.

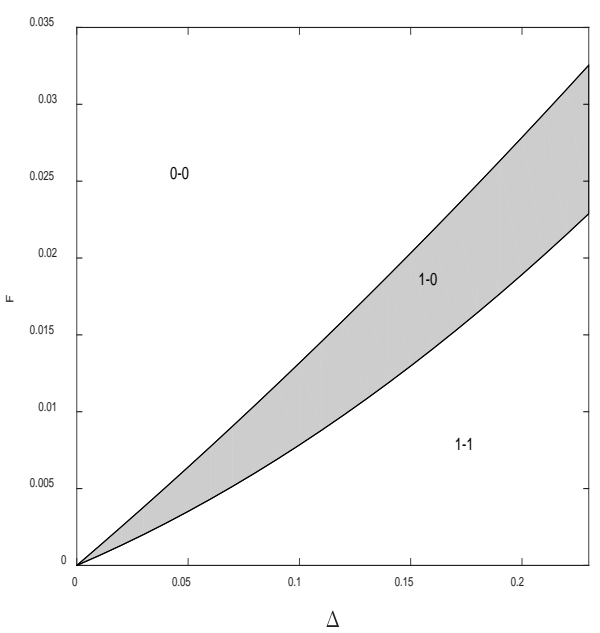

(a)

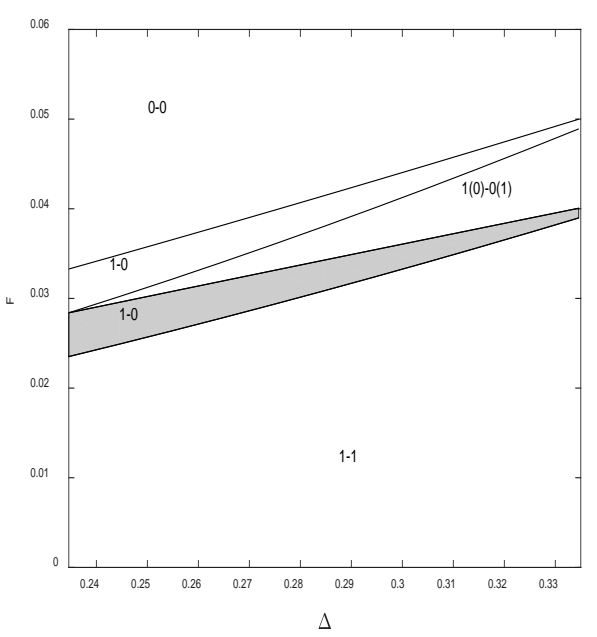

(b)

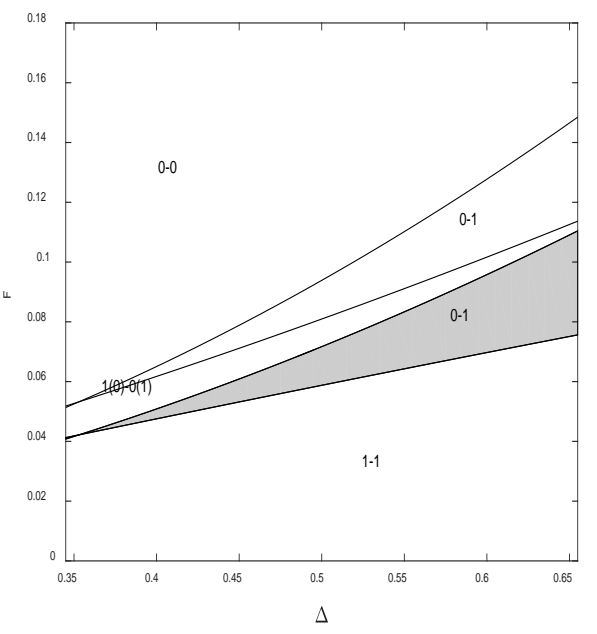


(c)

Fig. 2. The certification strategy regarding $\Delta$ and $F$ when $\theta=0.3 \cap \Delta \leq 1-\theta$.

Fig. 2 reflects the certification strategy regarding $\Delta$ and $F$ when $\theta=0.3 \cap$ $\Delta \leq 1-\theta$. Keeping $\Delta$ fixed, each figure in Fig.2 can be divided into different parts with the increase of $F$. Both suppliers adopt certification strategy when $F$ is low, and they both adopt no certification strategy when $F$ is high. The shaded parts in Fig. 2(a) and Fig. 2(b) shift from 1-0 to 0-1 in Fig. 2(c) (shaded area) due to the fact that supplier 2's brand recognition here is low, he will benefit more from certification with the increase of $\Delta$.

In Fig. 3, we assume $\Delta=0.3$ and $\Delta \leq 1-\theta$, when supplier 2's brand recognition is low $(\theta \leq 0.26)$, two suppliers will reach 0 -1 equilibrium with a moderate $F$ (shaded area in Fig. 3(a) and Fig. 3(b)). With the increase of $\theta$, the equilibrium will transform from 0-1 to 1-0 (shaded area in Fig. 3(c)).

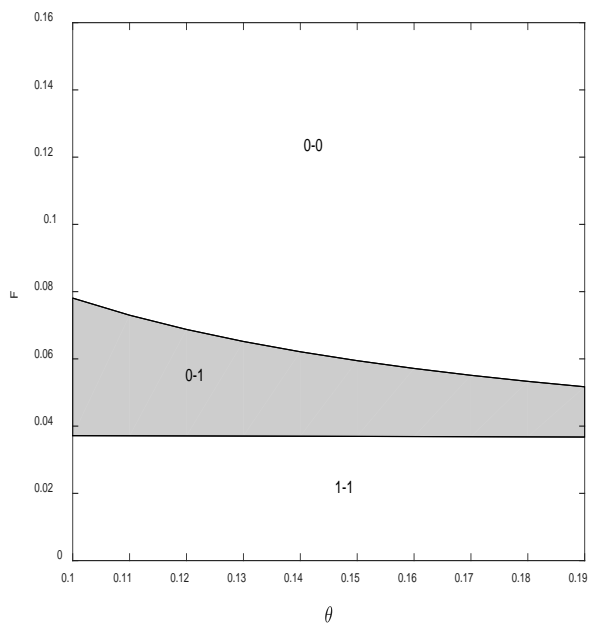

(a)

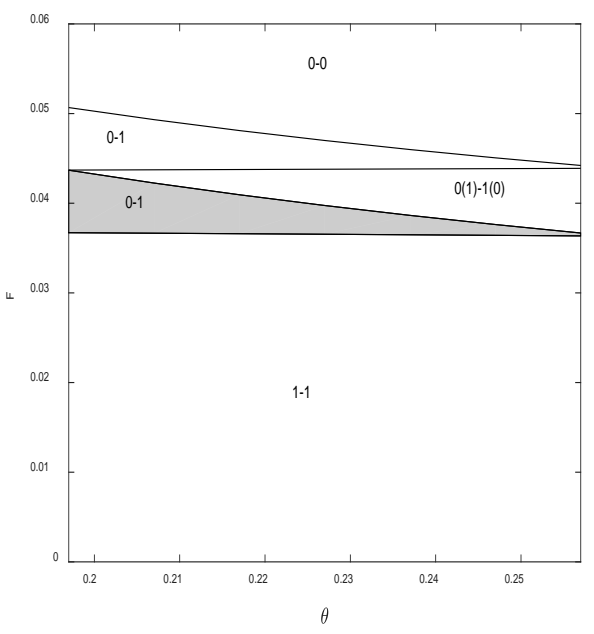

(b) 


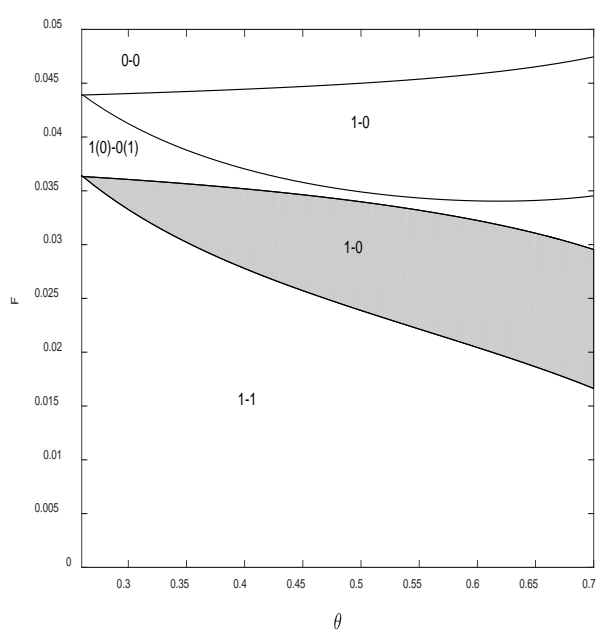

(c)

Fig. 3. The certification strategy regarding $\theta$ and $F$ when $\Delta=0.3 \cap \Delta \leq 1-\theta$.

When $1-\theta<\Delta \leq \min \{2-2 \theta, 1\}$, the retailer will only procure products 1 in the certification-no certification scenario. We have the final certification strategy as shown in Table 3.

Table 3. The organic certification strategy when $1-\theta<\Delta \leq \min \{2-2 \theta, 1\}$.

\begin{tabular}{|c|c|c|}
\hline$\theta$ & $\Delta$ & Case \\
\hline$\theta<\theta_{23}$ & & $(5)$ \\
\hline$\theta_{23}<\theta<\theta_{24}$ & $\Delta<\Delta_{23}$ & $(6)$ \\
\cline { 2 - 3 } & $\Delta>\Delta_{23}$ & $(5)$ \\
\hline$\theta_{24}<\theta<\theta_{21}$ & & $(6)$ \\
\hline \multirow{2}{*}{$\theta_{21}<\theta<\frac{5-\sqrt{17}}{2}$} & $\Delta<\Delta_{21}$ & $(7)$ \\
\cline { 2 - 3 } $5 \frac{5-\sqrt{17}}{2}<\theta<\theta_{22}$ & $\Delta<\Delta_{21}$ & $(6)$ \\
\cline { 2 - 3 } & $\Delta_{22}<\Delta<\Delta_{21}$ & $(8)$ \\
\cline { 2 - 3 } & $\Delta>\Delta_{21}$ & $(6)$ \\
\hline \multirow{2}{*}{$\theta_{22}<\theta<\frac{9-\sqrt{17}}{8}$} & $\Delta<\Delta_{22}$ & $(8)$ \\
\cline { 2 - 3 } & $\Delta>\Delta_{22}$ & $(7)$ \\
\hline \multirow{2}{*}{$\theta>\frac{9-\sqrt{17}}{8}$} & & $(8)$ \\
\hline
\end{tabular}

The equilibrium certification strategy can be seen in Appendix C.

From the equilibrium certification strategy of Table 3 in Appendix C, we find that if one of two suppliers has dominant strategy, two suppliers reach 0-1 equilibrium with moderate certification cost except for the Case (8). Actually, when $\frac{5-\sqrt{17}}{2}<\theta<$ 
$\frac{9-\sqrt{17}}{8}$ in Table 3, compared with the region of $\theta>\frac{5-\sqrt{17}}{2}$ in Table 2, we find supplier 1 is eager to certificate the product only when $\Delta<\Delta_{22}$ rather than always adopting certification strategy in the region of $\theta>\frac{5-\sqrt{17}}{2}$ in Table 2. In the region of $\frac{5-\sqrt{17}}{2}<$ $\theta<\frac{9-\sqrt{17}}{8} \cap \Delta<\Delta_{22}$, low health utility brings supplier 2 few benefits, while supplier 1 comes to realize the competition threaten from supplier 2 due to supplier 2's high brand recognition. Thus, the enthusiasm of certification for supplier 1 is stronger than that of supplier 2, and supplier 1 always adopts certification strategy regardless of the choice of supplier 2, supplier 2 has to take the contrary strategy- no certification due to the fact that if he also certificates the product, he can only obtain negative profit. Finally, supplier 2 will be quitted by the retailer, and his profit is zero.

Comparing Case (6) and Case (7), we find that the main difference generates in the fourth part, namely, when $\bar{F}_{22}<F \leq \bar{F}_{12}$ in Case (6) and when $\bar{F}_{12}<F \leq \bar{F}_{22}$ in Case (7). When $\Delta$ is high $\left(\Delta>\Delta_{21}\right)$ and $\bar{F}_{22}<F \leq \bar{F}_{12}$, no certification is supplier 1's dominant strategy since higher health utility is not too beneficial for supplier 1 under competition. When $\Delta$ is low $\left(\Delta<\Delta_{21}\right)$ and $\bar{F}_{12}<F \leq \bar{F}_{22}$, no certification is no longer supplier 1's dominant strategy, however, certification also cannot be supplier 1's dominant strategy due to high certification cost. Facing high certification cost and low health utility, no certification will be supplier 2's dominant strategy, thus, supplier 1 will adopt asymmetric certification strategy based on supplier 2's decision.

In this section, supplier 2 will face the risk of being quitted by the retailer if he does not certify the product. Therefore, we find that supplier 2 in this region is eager to certificate the product (see $0-1$ in Fig. 4). When the health utility is relatively low in Fig. 4(a), there exists one certification equilibrium without dominant strategy (shaded area), whereas this part will transform to $0-1$ in Fig. 4(b) due to the increase of $\Delta$. 


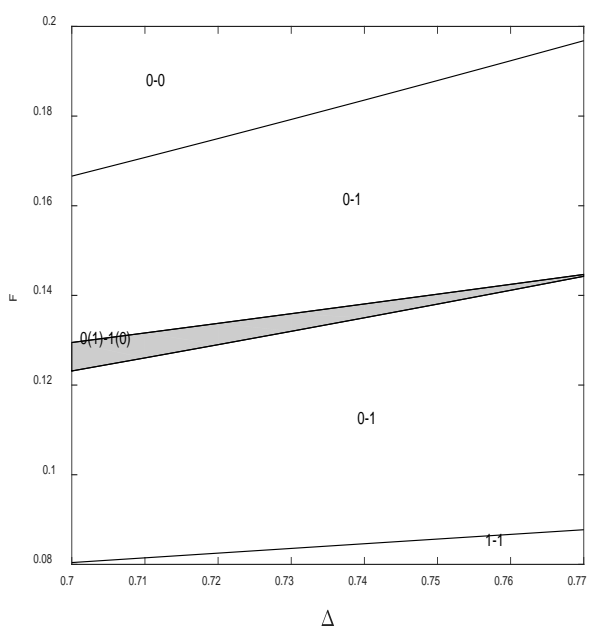

(a)

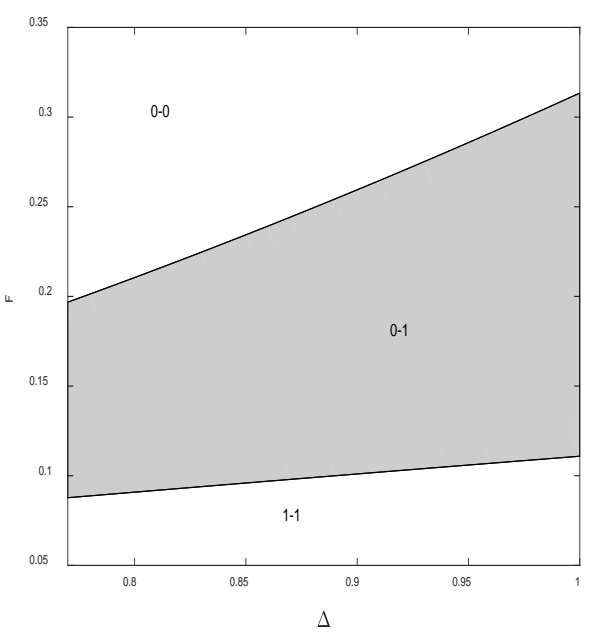

(b)

Fig. 4. The certification strategy regarding $\Delta$ and $F$ when $\theta=0.3 \cap 1-\theta<\Delta \leq$ $\min \{2-2 \theta, 1\}$.

When $2-2 \theta<\Delta \leq 1$ and $\theta>\frac{1}{2}$, if two suppliers take asymmetric certification strategies, the retailer will only procure products with organic label. We have the final certification strategy as shown in Table 4.

Table 4. The organic certification strategy when $2-2 \theta<\Delta \leq 1$.

\begin{tabular}{|c|c|c|}
\hline$\theta$ & $\Delta$ & Case \\
\hline$\frac{1}{2}<\theta<\frac{9-\sqrt{17}}{8}$ & & $(9)$ \\
\hline$\frac{9-\sqrt{17}}{8}<\theta \leq 1$ & $2-2 \theta<\Delta<\sqrt{\theta}$ & $(10)$ \\
\cline { 2 - 3 } & $\Delta>\sqrt{\theta}$ & $(9)$ \\
\hline
\end{tabular}

The equilibrium certification strategy can be seen in Appendix C.

In this region, when $F$ is moderate (see Cases (9) and (10) in Appendix C), facing supplier 2's high brand recognition and low health utility, two suppliers will reach 1-0 equilibrium, otherwise, they will reach 0-1 equilibrium. In Fig. 5, we assume $\Delta=1$ and $2-2 \theta<\Delta \leq 1$, both supplier 2's brand recognition and health utility from organic label are high here. We find that supplier 2 may still adopt certification strategy with a high brand recognition (shaded area in Fig. 5, where dark shadow and light shadow represent the equilibrium with and without dominant strategy, respectively). 


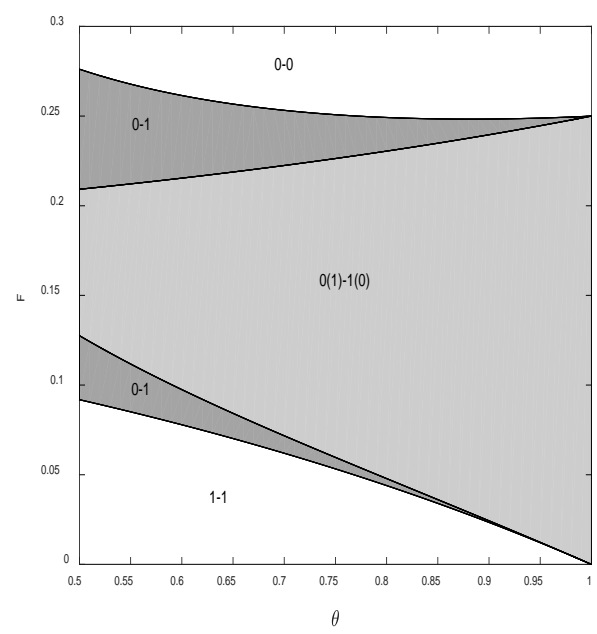

Fig. 5. The certification strategy regarding $\theta$ and $F$ when $\Delta=1 \cap 2-2 \theta<\Delta \leq 1$.

Proposition 4. When two suppliers both adopt certification strategy, they will fall into the prisoner's dilemma if the health utility from organic label is low and the certification cost is high.

When $F>\max \left\{\frac{\Delta(4+\Delta)(1-\theta)}{4(4-\theta)^{2}}, \frac{\Delta(1-\theta)(\Delta+\theta)}{(4-\theta)^{2} \theta}\right\}$ in the certification-certification strategy, two suppliers will fall into the prisoner's dilemma. From the proof in Appendix B, we find that two suppliers will fall in the prisoner's dilemma in the following conditions: if $\frac{\Delta(1-\theta)(\Delta+\theta)}{(4-\theta)^{2} \theta}<F<\bar{F}_{13}$ and $\Delta<\frac{4(1-\theta) \theta}{4-(4-\theta)(2-\theta) \theta}$ in Cases (3) (7); if $\frac{\Delta(1-\theta)(\Delta+\theta)}{(4-\theta)^{2} \theta}<F<\bar{F}_{11}$ in Cases (1) and (2); if $\frac{\Delta(1-\theta)(\Delta+\theta)}{(4-\theta)^{2} \theta}<F<\bar{F}_{21}$ in Cases (8) and (10); if $\frac{\Delta(1-\theta)(\Delta+\theta)}{(4-\theta)^{2} \theta}<F<\bar{F}_{33}$ and $\Delta<2 \sqrt{\frac{\theta}{4-\theta}}$ in Case (9). When the certification cost is very small, certification will still benefit both suppliers, which means that the prisoner's dilemma is common when the certification cost is relatively expensive. The findings of the prisoner's dilemma in organic certification are similar to Beuchelt and Zeller (2011) which shows that organic and organic-fairtrade farmers have become poorer relative to conventional producers.

\section{Proposition 5.}

(i) When $F$ is very low, two suppliers will both adopt certification strategy; when $F$ is very high, two suppliers will both adopt no certification strategy.

(ii) When $F$ is moderate, the supplier with low brand recognition will be more eager 
to obtain the organic label with higher risk of being quitted by the retailer.

Each case can be divided into 5 parts with the increase of $F$, which shows that two suppliers will reach 1-1 equilibrium in the first part, and reach 0-0 equilibrium in the fifth part (see Appendix C). In other parts (i.e., the certification cost is moderate), the certification strategies are different in Tables 2-4: in Table 2, we find that two suppliers will reach 0-1 equilibrium in Cases (3) and (4) which show supplier 2's low brand recognition and high health utility. In Table 3, two suppliers will reach 0-1 equilibrium in Cases (5)-(7). We find that supplier 2 will also certify the product in the condition with low health utility and brand recognition. In Table 4, two suppliers will reach 0-1 equilibrium in Case (9). We find that supplier 2 will certify the product even in the condition with high health utility and brand recognition (e.g. $\frac{9-\sqrt{17}}{8}<\theta \leq$ 1 and $\Delta>\sqrt{\theta}$ in Case (9)). The retailer will procure from two suppliers regardless of their organic label in Table 2, and he will only procure from supplier 1 if two suppliers adopt certification-no certification (1-0) strategy in Table 3, he will procure from the supplier with organic label if two suppliers adopt asymmetric certification strategy in Table 4. In other words, the competition intensity is gradually increasing in three tables. Comparing three tables, we can obtain Proposition 5(ii).

Proposition 6. When the retailer procures from two suppliers simultaneously regardless of the organic label, supplier 2 can obtain more profits than supplier 1 by organic certification with relatively low competition intensity and high health utility from organic label.

From the proof in the Appendix B, we find that when two suppliers both certify the product in Table 2, supplier 2 may obtain more profits than the rival by organic certification if $\theta<\frac{7-\sqrt{41}}{2}$ in Cases (3) and (4), and if $\frac{7-\sqrt{41}}{2}<\theta<\frac{5-\sqrt{17}}{2}$ in Case (3). When two suppliers adopt no certification-certification strategy in Table 2, supplier 2 may obtain more profits than the rival by organic certification if $\theta<\frac{7-\sqrt{41}}{2}$ in Cases (3) and (4), $\frac{7-\sqrt{41}}{2}<\theta<\frac{5-\sqrt{17}}{2}$ in Cases (2) and (3) and if $\frac{5-\sqrt{17}}{2}<\theta<\theta_{31}\left(\theta_{31} \approx\right.$ 0.484) in Case (2). These conditions include low competition intensity and high health utility. Supplier 1 will always obtain more profits than supplier 2 except the 
above conditions.

\section{Conclusion}

Food safety has always been drawing attention from general public and government agencies. With the development of information technology and big data, customers now can obtain food safety information more easily than before. Certification as one way of information disclosure has been widely investigated in the field of empirical research. However, no researchers have studied the organic certification strategy under competition in the field of operations management. In this paper, we separate the production and certification strategy of organic food, and analyze the organic certification strategy of two suppliers with different brands whose product already satisfies the standard of organic certification. Suppliers have to pay certification cost to prove the product to be organic by getting an organic label, otherwise, their product will be considered as conventional which has no additional health utility. Customers are heterogeneous in their perception of brand valuation, while the health utility from organic label is the same due to the equivalence of organic standards. We identify the conditions under which the retailer should procure two products simultaneously or only one product, and also analyze the condition under which the suppliers should certify the product. We find that the supplier with low brand recognition can improve the deficiency in brand by organic certification. When the certification cost is moderate, the supplier with low brand recognition will be more eager than the rival to obtain the organic label with higher risk of being quitted by the retailer. Certification may not always benefit suppliers, when two suppliers adopt certification strategy simultaneously, they may fall into the prisoner's dilemma with relatively high certification cost and low health utility from organic label.

In future research, we will further investigate the certification strategy for the supplier whose product does not satisfy the organic standard. Thus, the supplier has to invest effort such as using organic fertilizers to meet the requirements of organic certification. Therefore, the decision of whether to produce the organic product or not and its resulting different environmental impacts will be considered. One can also 
investigate the influence of suppliers' corporate social responsibility on the decisions of production and certification. Furthermore, the customers may be heterogeneous on the health utility from organic label.

\section{Acknowledgements}

This work is supported by the National Natural Science Foundation of China (Nos. 71771053, 71628101 and 71371003) and the Key Research and Development Plan (Modern Agriculture) of Jiangsu Province (No. BE2018385).

\section{Appendix A1. The equilibrium prices for a given certification}

\section{strategy.}

We consider the situation of the retailer procuring two products, i.e., $\frac{p_{2}-\zeta_{2} \Delta}{p_{1}-\zeta_{1} \Delta} \leq$ $\theta \leq 1-p_{1}+p_{2}+\left(\zeta_{1}-\zeta_{2}\right) \Delta$

$\pi_{s 1}=w_{1}\left(1-\frac{w_{1}+m_{1}-\left(w_{2}+m_{2}\right)+\left(\zeta_{2}-\zeta_{1}\right) \Delta}{1-\theta}\right)-\zeta_{1} F$, $\pi_{s 2}=w_{2}\left(\frac{w_{1}+m_{1}-\left(w_{2}+m_{2}\right)+\left(\zeta_{2}-\zeta_{1}\right) \Delta}{1-\theta}-\frac{w_{2}+m_{2}-\zeta_{2} \Delta}{\theta}\right)-\zeta_{2} F$, let $\frac{\partial \pi_{s 1}}{\partial w_{1}}=\frac{\partial \pi_{s 2}}{\partial w_{2}}=0$, we obtain $w_{1}=\frac{2-2 \theta-(2-\theta) m_{1}+m_{2}+(2-\theta) \zeta_{1} \Delta-\zeta_{2} \Delta}{4-\theta}$ and $w_{2}=\frac{\theta m_{1}-(2-\theta) m_{2}+\theta\left(1-\theta-\zeta_{1} \Delta\right)+(2-\theta) \zeta_{2} \Delta}{4-\theta}$. Substituting $w_{1}$ and $w_{2}$ into (5), we get: $\pi_{r}=m_{1}\left(\frac{2-2 \theta-(2-\theta) m_{1}+m_{2}+(2-\theta) \zeta_{1} \Delta-\zeta_{2} \Delta}{(4-\theta)(1-\theta)}\right)+m_{2}\left(\frac{\theta m_{1}-(2-\theta) m_{2}+\theta\left(1-\theta-\zeta_{1} \Delta\right)+(2-\theta) \zeta_{2} \Delta}{(4-\theta)(1-\theta) \theta}\right)$, let $\frac{\partial \pi_{r}}{\partial m_{1}}=\frac{\partial \pi_{r}}{\partial m_{2}}=0$, we obtain $m_{2}^{*}=\frac{1}{2}\left(\theta+\zeta_{2} \Delta\right), m_{1}^{*}=\frac{1}{2}\left(1+\zeta_{1} \Delta\right)$. Replacing $m_{2}$ and $m_{1}$ with $m_{2}^{*}$ and $m_{1}^{*}$ into $w_{2}^{*}$ and $w_{1}^{*}$, then we have $w_{1}^{*}=\frac{2-2 \theta+(2-\theta) \zeta_{1} \Delta-\zeta_{2} \Delta}{2(4-\theta)}$ and $w_{2}^{*}=\frac{\theta\left(1-\theta-\zeta_{1} \Delta\right)+(2-\theta) \zeta_{2} \Delta}{2(4-\theta)}$. We further get equations (15) (19).

\section{Appendix A2. Certification strategy if $\theta=1$.}

If $\theta=1$, the utility a customer derives from product $n$ can be denoted as $u_{n}=$ $v-p_{n}+\zeta_{n} \Delta$, the equilibrium price will satisfy $p_{2}-p_{1}=\left(\zeta_{2}-\zeta_{1}\right) \Delta$. If not, the demand of one supplier will be zero, so this supplier will adjust his wholesale price to satisfy $p_{2}-p_{1}=\left(\zeta_{2}-\zeta_{1}\right) \Delta$. The customer will purchase the product if $u_{n} \geq 0$, the 
overall demand will be $D=1-p_{n}+\zeta_{n} \Delta$, and the final demand for supplier $n$ will be split equally, which can be denoted as $D_{n}=\frac{1-p_{n}+\zeta_{n} \Delta}{2}$. By maximizing $\pi_{s n}=$ $\left(\frac{1-\left(w_{n}+m_{n}\right)+\zeta_{n} \Delta}{2}\right) w_{n}$, we get $w_{n}^{*}=\frac{1}{2}\left(1-m_{n}+\Delta \zeta_{n}\right)$. Substituting $w_{n}^{*}$ into $\pi_{r}=$ $\sum_{n=1}^{2}\left(\frac{1-\left(w_{n}+m_{n}\right)+\zeta_{n} \Delta}{2}\right) m_{n}$ and making $\frac{\partial \pi_{r}}{\partial m_{n}}=0$, we get $m_{n}^{*}=\frac{1}{2}\left(1+\Delta \zeta_{n}\right)$. Substituting $m_{n}^{*}$ into $w_{n}^{*}$, we get $w_{n}^{*}=\frac{1}{4}\left(1+\Delta \zeta_{n}\right)$ and $p_{n}^{*}=\frac{3}{4}\left(1+\Delta \zeta_{n}\right)$. By substituting $p_{n}^{*}$ into the constraint of $p_{2}-p_{1}=\left(\zeta_{2}-\zeta_{1}\right) \Delta$, we get $\zeta_{1}=\zeta_{2}$. The suppliers will certify the product if $\pi_{s n}\left(\zeta_{n}=1\right)-\pi_{s n}\left(\zeta_{n}=0\right)>0$, i.e., $F<$ $\frac{1}{32} \Delta(2+\Delta)$

\section{Appendix B.}

\section{Proof of Lemma 1}

(i) $\frac{\partial w_{1}^{*}}{\partial \theta}=-\frac{6+2 \Delta \zeta_{1}+\Delta \zeta_{2}}{2(4-\theta)^{2}}<0$, $\frac{\partial \pi_{s 1}^{*}}{\partial \theta}=\frac{\left(2-2 \theta+\Delta(2-\theta) \zeta_{1}-\Delta \zeta_{2}\right)\left(2\left(-2+\theta+\theta^{2}\right)+\Delta(4-(2-\theta) \theta) \zeta_{1}-3 \Delta(2-\theta) \zeta_{2}\right)}{4(4-\theta)^{3}(1-\theta)^{2}}<0$.

(ii) $\frac{\partial w_{2}^{*}}{\partial \theta}=\frac{4-(8-\theta) \theta-2 \Delta\left(2 \zeta_{1}+\zeta_{2}\right)}{2(4-\theta)^{2}}$, when $\Delta=0$, the maximum of $\frac{\partial w_{2}^{*}}{\partial \theta}$ equals $\frac{4-(8-\theta) \theta}{2(4-\theta)^{2}}$, thus, we find that when $\theta>4-2 \sqrt{3}, \frac{\partial w_{2}^{*}}{\partial \theta}<0$, when $\theta<4-2 \sqrt{3}$, if $\Delta<\frac{4-8 \theta+\theta^{2}}{4 \zeta_{1}+2 \zeta_{2}}$, $\frac{\partial w_{2}^{*}}{\partial \theta}>0$, else, $\frac{\partial w_{2}^{*}}{\partial \theta}<0$.

(iii) In scenario $\mathrm{I}, \zeta_{1}=\zeta_{2}=1$, after substituting $p_{1}^{*}$ and $p_{2}^{*}$ into the constraint $\frac{p_{2}-\zeta_{2} \Delta}{p_{1}-\zeta_{1} \Delta} \leq \theta \leq 1-p_{1}+p_{2}+\left(\zeta_{1}-\zeta_{2}\right) \Delta$, we get that the retailer will procure two products simultaneously. In scenario II, $\zeta_{1}=1, \zeta_{2}=0$, after substituting $p_{1}^{*}$ and $p_{2}^{*}$ into the constraint $\frac{p_{2}-\zeta_{2} \Delta}{p_{1}-\zeta_{1} \Delta} \leq \theta \leq 1-p_{1}+p_{2}+\left(\zeta_{1}-\zeta_{2}\right) \Delta$, we get that the retailer will procure two products simultaneously if $\Delta \leq 1-\theta$; otherwise, he will only procure products from supplier 1 .

$$
\pi_{s 2}^{*}=\frac{\left(\theta(-1+\theta+\Delta)-(2-\theta) \zeta_{2} \Delta\right)^{2}}{4(4-\theta)^{2}(1-\theta) \theta}-\zeta_{2} F, \frac{\partial \pi_{s 2}^{*}}{\partial \theta}=\frac{\left(\theta(1-\Delta-\theta)+\Delta(2-\theta) \zeta_{2}\right) f_{1}(\Delta)}{4(4-\theta)^{3}(1-\theta)^{2} \theta^{2}},
$$

$f_{1}(\Delta)=4 \theta-11 \theta^{2}+7 \theta^{3}+\Delta\left(18 \theta \zeta_{2}+2 \theta^{3} \zeta_{2}+2 \theta^{3}-4 \theta-\theta^{2}-9 \theta^{2} \zeta_{2}-8 \zeta_{2}\right)$.

Since $\frac{\partial f_{1}(\Delta)}{\partial \Delta}<0$, the maximum of $f_{1}(\Delta)$ which equals $4 \theta-11 \theta^{2}+7 \theta^{3}$ is 
obtained at $\Delta=0$. The minimum of $f_{1}(\Delta)$ which equals $(-1+\theta)(8+\theta(-10+$ $11 \theta)$ ) in scenario I and $-2(4-\theta)(1-\theta) \theta^{2}$ in scenario II is obtained at $\Delta=1$ and $\Delta=1-\theta$ respectively. We find that the minimum of $f_{1}(\Delta)$ in scenario I and II is less than 0 . Thus, when $\theta>\frac{4}{7}, f_{1}(\Delta=0)<0$, $\frac{\partial \pi_{s 2}^{*}}{\partial \theta}<0$, when $\theta<\frac{4}{7}$, if $\Delta<$ $\frac{(1-\theta) \theta(-4+7 \theta)}{\theta(-4+\theta(-1+2 \theta))+(-8+\theta(18+\theta(-9+2 \theta))) \zeta_{2}}, \frac{\partial \pi_{s 2}^{*}}{\partial \theta}>0$, else, $\frac{\partial \pi_{s 2}^{*}}{\partial \theta}<0$.

In scenario I, $p_{1}^{*}-p_{2}^{*}=\frac{(1-\theta)(6-\Delta-2 \theta)}{2(4-\theta)}>0, \frac{\partial p_{1}^{*}-p_{2}^{*}}{\partial \Delta}=\frac{1-\theta}{2(-4+\theta)}<0, \frac{\partial p_{1}^{*}-p_{2}^{*}}{\partial \theta}=$ $\frac{3(2+\Delta)-2(4-\theta)^{2}}{2(4-\theta)^{2}}<0 . D_{1}^{*}=\frac{2+\Delta}{8-2 \theta}, \frac{\partial D_{1}^{*}}{\partial \theta}>0, D_{2}^{*}=\frac{2 \Delta+\theta}{8 \theta-2 \theta^{2}}$, if $\Delta<\frac{\theta^{2}}{8-4 \theta}, \frac{\partial D_{2}^{*}}{\partial \theta}>0$, else, $\frac{\partial D_{2}^{*}}{\partial \theta}<0 . D_{1}^{*}-D_{2}^{*}=\frac{\Delta(-2+\theta)+\theta}{2(4-\theta) \theta}$, if $\theta>\frac{2 \Delta}{1+\Delta}, D_{1}^{*}>D_{2}^{*}$, else, $D_{1}^{*}<D_{2}^{*}, \frac{\partial D_{1}^{*}-D_{2}^{*}}{\partial \theta}=$ $\frac{1}{4}\left(\frac{2+\Delta}{(4-\theta)^{2}}+\frac{\Delta}{\theta^{2}}\right)>0$

(iv) In scenario III, $\zeta_{1}=0, \zeta_{2}=1, \pi_{s 2}^{*}=\frac{(\theta(1-\theta)+(2-\theta) \Delta)^{2}}{4(4-\theta)^{2}(1-\theta) \theta}-\zeta_{2} F$. After substituting $p_{1}^{*}$ and $p_{2}^{*}$ into the constraint $\frac{p_{2}-\zeta_{2} \Delta}{p_{1}-\zeta_{1} \Delta} \leq \theta \leq 1-p_{1}+p_{2}+\left(\zeta_{1}-\zeta_{2}\right) \Delta$, we get that the retailer will procure two products simultaneously if $\Delta \leq 2-2 \theta$; otherwise, he will only procure products from supplier 2.

$$
\frac{\partial \pi_{s 2}^{*}}{\partial \theta}=\frac{(\Delta(2-\theta)+(1-\theta) \theta) f_{2}(\Delta)}{4(4-\theta)^{3}(1-\theta)^{2} \theta^{2}} \quad, \quad f_{2}(\Delta)=(1-\theta) \theta(4-7 \theta)+\Delta(-8+\theta(18+
$$
$\theta(-9+2 \theta))), f_{2}(\Delta=0)=(1-\theta) \theta(4-7 \theta)$, if $\theta>\frac{4}{7}, f_{2}(\Delta=0)<0$, else, $f_{2}(\Delta=0)>0 . f_{2}(\Delta=2-2 \theta)=-(4-\theta)(1-\theta)(4-\theta(9-4 \theta))$, if $\theta>\frac{9-\sqrt{17}}{8}$, $f_{2}(\Delta=2-2 \theta)>0$, else, $f_{2}(\Delta=2-2 \theta)<0$. Thus, we get that when $\theta<\frac{4}{7}$, if $\Delta<\frac{(1-\theta) \theta(-4+7 \theta)}{-8+\theta(18+\theta(-9+2 \theta))}, \frac{\partial \pi_{S 2}^{*}}{\partial \theta}>0$, else, $\frac{\partial \pi_{S 2}^{*}}{\partial \theta}<0$; when $\frac{4}{7}<\theta<\frac{9-\sqrt{17}}{8}, \frac{\partial \pi_{S 2}^{*}}{\partial \theta}<0$; when $\theta>\frac{9-\sqrt{17}}{8}$, if $\Delta<\frac{(1-\theta) \theta(-4+7 \theta)}{-8+\theta(18+\theta(-9+2 \theta))}$, $\frac{\partial \pi_{S 2}^{*}}{\partial \theta}<0$, else, $\frac{\partial \pi_{S 2}^{*}}{\partial \theta}>0$.

In scenario IV, $\zeta_{1}=\zeta_{2}=0, \frac{\partial \pi_{S 2}^{*}}{\partial \theta}=\frac{4-7 \theta}{4(4-\theta)^{3}}$, if $\theta<\frac{4}{7}, \frac{\partial \pi_{s 2}^{*}}{\partial \theta}>0$, else, $\frac{\partial \pi_{s 2}^{*}}{\partial \theta}<0$. Proof of Proposition 1

(i) $\frac{\partial \pi_{r}^{*}}{\partial \theta}=\frac{f_{3}(\Delta)}{8(4-\theta)^{2} \theta^{2}}, \quad f_{3}(\Delta)=\Delta^{2}\left(8 \theta-16+2 \theta^{2}\right)+12 \Delta \theta^{2}+12 \theta^{2}, f_{3}(\Delta=1)=$ $-16+8 \theta+26 \theta^{2}$, if $\theta>\frac{2}{13}(3 \sqrt{3}-1), f_{3}(\Delta=1)>0$, thus, $\frac{\partial \pi_{r}^{*}}{\partial \theta}>0$; if $\theta<$ 
$\frac{2}{13}(3 \sqrt{3}-1), f_{3}(\Delta=1)<0$, if $\Delta<\Delta_{r}^{*}, f_{3}(\Delta)>0$, thus, $\frac{\partial \pi_{r}^{*}}{\partial \theta}>0$; if $\Delta>\Delta_{r}^{*}$, $\frac{\partial \pi_{r}^{*}}{\partial \theta}<0$.

(ii) $\frac{\partial \pi_{s c}^{*}}{\partial \theta}=\frac{f_{4}(\Delta)}{4(4-\theta)^{3} \theta^{2}}, f_{4}(\Delta)=2 \Delta \theta^{2}(4-7 \theta)+\theta^{2}(20-17 \theta)+2 \Delta^{2}(\theta(18-\theta(5+$ $\theta))-24), f_{4}(\Delta=1)=-48+3 \theta(12+(6-11 \theta) \theta)<0$, if $\Delta<\frac{(4-7 \theta) \theta^{2}+\theta \sqrt{3(-4+\theta)^{2}(20-\theta(22-5 \theta))}}{2(24+\theta(-18+\theta(5+\theta)))}, \frac{\partial \pi_{s c}^{*}}{\partial \theta}>0$, else, $\frac{\partial \pi_{s c}^{*}}{\partial \theta}<0$.

(iii) $E(C S)=\frac{2 \Delta \theta(8+\theta)+\left(\Delta^{2}+\theta\right)(4+5 \theta)}{8(4-\theta)^{2} \theta}, \frac{\partial E(C S)}{\partial \theta}=\frac{f_{5}(\Delta)}{8(4-\theta)^{3} \theta^{2}}, f_{5}(\Delta)=2 \Delta \theta^{2}(20+\theta)+$ $2 \Delta^{2}(2+\theta)(-4+5 \theta)+\theta^{2}(28+5 \theta), f_{5}(\Delta=1)=-16+\theta(12+\theta(78+7 \theta))$, when $\theta>\frac{4}{5}, f_{5}(\Delta)>0$, when $\theta<\frac{4}{5}$, we let $-16+\theta_{c S}^{*}\left(12+\theta_{c S}^{*}\left(78+7 \theta_{c S}^{*}\right)\right)=0$, if $\theta<\theta_{c S}^{*}, f_{5}(\Delta=1)<0$, if $\theta>\theta_{c S}^{*}, f_{5}(\Delta=1)>0$. Thus, we get if $\theta>\theta_{c S}^{*}$, $\frac{\partial E(C S)}{\partial \theta}>0$; otherwise, it increases in $\theta$ when $\Delta<\Delta_{c S}^{*}$ and decreases in $\theta$ when $\Delta>\Delta_{c s}^{*}$

Proof of Proposition 2

Since $D_{1}^{*}-D_{2}^{*}=\frac{\theta-\Delta(2-\theta)}{2(4-\theta) \theta}$, we get if $\Delta<\frac{\theta}{2-\theta}, D_{1}^{*}>D_{2}^{*}$, if $\Delta>\frac{\theta}{2-\theta}, D_{1}^{*}<D_{2}^{*}$, $\frac{\partial D_{1}^{*}-D_{2}^{*}}{\partial \Delta}=\frac{-(2-\theta)}{2(4-\theta) \theta}<0, \frac{\partial D_{1}^{*}-D_{2}^{*}}{\partial \theta}=\frac{1}{4}\left(\frac{2+\Delta}{(4-\theta)^{2}}+\frac{\Delta}{\theta^{2}}\right)>0 \cdot \frac{\partial \pi_{s 1}^{*}}{\partial \Delta}=\frac{(2+\Delta)(1-\theta)}{2(4-\theta)^{2}}>0, \frac{\partial \pi_{s 2}^{*}}{\partial \Delta}=$ $\frac{(1-\theta)(2 \Delta+\theta)}{(4-\theta)^{2} \theta}>0, \pi_{s 1}^{*}-\pi_{s 2}^{*}=\frac{\left(\Delta^{2}-\theta\right)(1-\theta)}{4(-4+\theta) \theta}$, if $\Delta>\sqrt{\theta}, \pi_{s 1}^{*}<\pi_{s 2}^{*}$, if $\Delta<\sqrt{\theta}, \pi_{s 1}^{*}>$ $\pi_{S 2}^{*} \cdot \frac{\partial \pi_{S 1}^{*}}{\partial \Delta}-\frac{\partial \pi_{S 2}^{*}}{\partial \Delta}=\frac{\Delta(1-\theta)}{2(-4+\theta) \theta}<0 . p_{1}^{*}-p_{2}^{*}=\frac{(1-\theta)(6-\Delta-2 \theta)}{2(4-\theta)}>0, \frac{\partial p_{1}^{*}-p_{2}^{*}}{\partial \Delta}=-\frac{(1-\theta)}{2(4-\theta)}<0$.

Compared with the scenario that they both do not certify the product, the increase of supplier 1's profit can be denoted by $\pi_{\Delta s 1}^{*}=\pi_{s 1}^{*}\left(\delta_{1}=\delta_{2}=1\right)-$ $\pi_{S 1}^{*}\left(\delta_{1}=\delta_{2}=0\right)=\frac{\Delta(4+\Delta)(1-\theta)}{4(4-\theta)^{2}}$, the increase of supplier 2's profit can be denoted by $\pi_{\Delta s 2}^{*}=\pi_{s 2}^{*}\left(\delta_{1}=\delta_{2}=1\right)-\pi_{s 2}^{*}\left(\delta_{1}=\delta_{2}=0\right)=\frac{\Delta(1-\theta)(\Delta+\theta)}{(4-\theta)^{2} \theta} . \frac{\partial \pi_{\Delta s 1}^{*}}{\partial \theta}=\frac{\Delta(4+\Delta)(2+\theta)}{4(-4+\theta)^{3}}<$ $0, \frac{\partial \pi_{\Delta s 2}^{*}}{\partial \theta}=\frac{\Delta\left(\theta^{2}(2+\theta)+\Delta(4-\theta(3-2 \theta))\right)}{(-4+\theta)^{3} \theta^{2}}<0$.

\section{Proof of Proposition 3}

When $\delta_{1}=\delta_{2}=1$ or $\delta_{1}=\delta_{2}=0$, we find that $p_{1}^{*}$ and $p_{2}^{*}$ always satisfy $\frac{p_{2}-\zeta_{2} \Delta}{p_{1}-\zeta_{1} \Delta} \leq \theta \leq 1-p_{1}+p_{2}+\left(\zeta_{1}-\zeta_{2}\right) \Delta$; when $\delta_{1}=1, \delta_{2}=0, p_{1}^{*}$ and $p_{2}^{*}$ will 
satisfy the above constraint if $\Delta \leq 1-\theta$; when $\delta_{1}=0, \delta_{2}=1, p_{1}^{*}$ and $p_{2}^{*}$ will satisfy the above constraint if $\Delta \leq 2-2 \theta$.

When $\delta_{1}=\delta_{2}=1, \frac{\partial w_{1}^{*}}{\partial \Delta}=\frac{1-\theta}{2(4-\theta)}>0, \frac{\partial w_{2}^{*}}{\partial \Delta}=\frac{1-\theta}{(4-\theta)}>0, \frac{\partial p_{1}^{*}}{\partial \Delta}=\frac{5-2 \theta}{2(4-\theta)}>$ $0, \frac{\partial p_{2}^{*}}{\partial \Delta}=\frac{6-3 \theta}{2(4-\theta)}>0, \frac{\partial \pi_{s 1}^{*}}{\partial \Delta}=\frac{2-2 \theta+\Delta-\Delta \theta}{2(-4+\theta)^{2}}>0, \frac{\partial \pi_{s 2}^{*}}{\partial \Delta}=\frac{\Delta(2-\theta)+\theta(1-\Delta-\theta)}{(4-\theta)^{2} \theta}>0, \frac{\partial \pi_{r}^{*}}{\partial \Delta}=$ $\frac{\Delta(2-\theta) \theta+2 \theta(1-\theta-\Delta)+((1-\theta) \theta+\Delta(2-\theta))}{2(4-\theta)(1-\theta) \theta}>0 ;$ When $\delta_{1}=1, \delta_{2}=0, \frac{\partial w_{1}^{*}}{\partial \Delta}=\frac{(2-\theta)}{2(4-\theta)}>$ $0, \frac{\partial w_{2}^{*}}{\partial \Delta}=\frac{\theta}{2(-4+\theta)}<0, \frac{\partial p_{1}^{*}}{\partial \Delta}=\frac{3-\theta}{4-\theta}>0, \frac{\partial p_{2}^{*}}{\partial \Delta}=\frac{\theta}{2(-4+\theta)}<0, \frac{\partial \pi_{s 1}^{*}}{\partial \Delta}=\frac{(2-\theta)(2-2 \theta-\Delta(2-\theta))}{2(4-\theta)^{2}(1-\theta)}>$ $0, \frac{\partial \pi_{S 2}^{*}}{\partial \Delta}=\frac{(\theta(-1+\theta+\Delta))}{2(4-\theta)^{2}(1-\theta)}<0, \frac{\partial \pi_{r}^{*}}{\partial \Delta}=\frac{\Delta(2-\theta) \theta+2 \theta(1-\theta)}{2(4-\theta)(1-\theta) \theta}>0$; When $\delta_{1}=0, \delta_{2}=1$, $\frac{\partial w_{1}^{*}}{\partial \Delta}=\frac{1}{2(-4+\theta)}<0, \frac{\partial w_{2}^{*}}{\partial \Delta}=\frac{2-\theta}{2(4-\theta)}>0, \frac{\partial p_{1}^{*}}{\partial \Delta}=\frac{1}{2(-4+\theta)}<0, \frac{\partial p_{2}^{*}}{\partial \Delta}=\frac{3-\theta}{4-\theta}>0, \frac{\partial \pi_{s 1}^{*}}{\partial \Delta}=$ $\frac{(-2+2 \theta+\Delta)}{2(4-\theta)^{2}(1-\theta)}<0, \frac{\partial \pi_{S 2}^{*}}{\partial \Delta}=\frac{(2-\theta)(\theta(1-\theta)+\Delta(2-\theta))}{2(4-\theta)^{2}(1-\theta) \theta}>0, \frac{\partial \pi_{r}^{*}}{\partial \Delta}=\frac{\Delta(2-\theta) \theta+2 \theta(1-\theta)}{2(4-\theta)(1-\theta) \theta}>0$.

\section{Proof of Proposition 4}

We first consider the condition that $\Delta \leq 1-\theta$, the retailer will procure the products from two suppliers regardless of their organic label. To simplify the exposition, we use $\pi_{s 2 y y}^{*}$ to represent supplier 2's profit in the certification-certification scenario, similar symbols can be used to represent two suppliers' profit in different certification scenarios.

For supplier 2, given that supplier 1 adopts certification, supplier 2 adopts certification if $\pi_{s 2 y y}^{*}>\pi_{s 2 y n}^{*}$, otherwise no certification; given that supplier 1 adopts no certification, supplier 2 adopts certification if $\pi_{s 2 n y}^{*}>\pi_{s 2 n n}^{*}$, otherwise no certification. For supplier 1, given that supplier 2 adopts certification, supplier 1 adopts certification if $\pi_{s 1 y y}^{*}>\pi_{s 1 n y}^{*}$, otherwise no certification; given that supplier 2 adopts no certification, supplier 1 adopts certification if $\pi_{s 1 y n}^{*}>\pi_{s 1 n n}^{*}$, otherwise no certification.

By equating $\pi_{s 2 y y}^{*}$ and $\pi_{s 2 y n}^{*}$, we get the threshold certification cost $\bar{F}_{11}=$ $\frac{\Delta(2-\theta)(2(1-\theta) \theta+\Delta(2-3 \theta))}{4(4-\theta)^{2}(1-\theta) \theta}$; by equating $\pi_{s 2 n y}^{*}$ and $\pi_{s 2 n n}^{*}$, we get $\bar{F}_{12}=$ 
$\frac{\Delta(2-\theta)(\Delta(2-\theta)+2(1-\theta) \theta)}{4(4-\theta)^{2}(1-\theta) \theta}$; by equating $\pi_{s 1 y y}^{*}$ and $\pi_{s 1 n y}^{*}$, we get $\bar{F}_{13}=\frac{\Delta(2-\theta)(4-(4+\Delta) \theta)}{4(4-\theta)^{2}(1-\theta)}$; by equating $\pi_{s 1 y n}^{*}$ and $\pi_{s 1 n n}^{*}$, we get $\bar{F}_{14}=\frac{\Delta(2-\theta)(2(2+\Delta)-(4+\Delta) \theta)}{4(4-\theta)^{2}(1-\theta)}$.

Since $\frac{\bar{F}_{12}}{\bar{F}_{13}}=\frac{\Delta(2-\theta)+2(1-\theta) \theta}{(4-(4+\Delta) \theta) \theta}$, we get if $\Delta<\Delta_{11}=-2+\frac{4}{2+(-1+\theta) \theta}, \bar{F}_{12}<\bar{F}_{13}$, else, $\bar{F}_{12}>\bar{F}_{13}$. Since $\frac{\bar{F}_{11}}{\bar{F}_{13}}=\frac{(2(1-\theta) \theta+\Delta(2-3 \theta))}{\theta(4-(4+\Delta) \theta)}$, we get when $\theta>\frac{5-\sqrt{17}}{2} \approx 0.438$, $\bar{F}_{11}<\bar{F}_{13}$, when $\theta<\frac{5-\sqrt{17}}{2}$, if $\Delta<\Delta_{12}=\frac{2 \theta}{2-\theta}, \bar{F}_{11}<\bar{F}_{13}$, else if $\Delta>\Delta_{12}, \bar{F}_{11}>$ $\bar{F}_{13}$. Since $\frac{\bar{F}_{12}}{\bar{F}_{14}}=\frac{\Delta(2-\theta)+2(1-\theta) \theta}{\theta(2(2+\Delta)-(4+\Delta) \theta)}$, we get when $\theta>\frac{5-\sqrt{17}}{2}, \bar{F}_{12}<\bar{F}_{14}$, when $\theta<$ $\frac{5-\sqrt{17}}{2}$, if $\Delta<\Delta_{12}=\frac{2 \theta}{2-\theta}, \quad \bar{F}_{12}<\bar{F}_{14}$, else if $\Delta>\Delta_{12}, \quad \bar{F}_{12}>\bar{F}_{14}$. Since $\frac{\bar{F}_{11}}{\bar{F}_{14}}=$ $\frac{(2(1-\theta) \theta+\Delta(2-3 \theta))}{\theta(2(2+\Delta)-(4+\Delta) \theta)}$, we get when $\theta>\frac{7-\sqrt{41}}{2} \approx 0.298, \bar{F}_{11}<\bar{F}_{14}$, when $\theta<\frac{7-\sqrt{41}}{2}$, if $\Delta<\Delta_{13}=\frac{2(1-\theta) \theta}{2-(5-\theta) \theta}, \quad \bar{F}_{11}<\bar{F}_{14}$, else if $\Delta>\Delta_{13}, \bar{F}_{11}>\bar{F}_{14}$. In conclusion, we obtain the following results:

In the region of $\theta<\frac{7-\sqrt{41}}{2}$ : when $\Delta<\Delta_{11}$, we get $\bar{F}_{11}<\bar{F}_{12}<\bar{F}_{13}<\bar{F}_{14}$; when $\Delta_{11}<\Delta<\Delta_{12}$, we get $\bar{F}_{11}<\bar{F}_{13}<\bar{F}_{12}<\bar{F}_{14}$; when $\Delta_{12}<\Delta<\Delta_{13}$, we get $\bar{F}_{13}<\bar{F}_{11}<\bar{F}_{14}<\bar{F}_{12}$; when $\Delta>\Delta_{13}$, we get $\bar{F}_{13}<\bar{F}_{14}<\bar{F}_{11}<\bar{F}_{12}$.

In the region of $\frac{7-\sqrt{41}}{2}<\theta<\frac{5-\sqrt{17}}{2}$ : when $\Delta<\Delta_{11}$, we get $\bar{F}_{11}<\bar{F}_{12}<\bar{F}_{13}<$ $\bar{F}_{14}$; when $\Delta_{11}<\Delta<\Delta_{12}$, we get $\bar{F}_{11}<\bar{F}_{13}<\bar{F}_{12}<\bar{F}_{14}$; when $\Delta>\Delta_{12}$, we get $\bar{F}_{13}<\bar{F}_{11}<\bar{F}_{14}<\bar{F}_{12}$.

In the region of $\theta>\frac{5-\sqrt{17}}{2}$ : when $\Delta<\Delta_{11}$, we get $\bar{F}_{11}<\bar{F}_{12}<\bar{F}_{13}<\bar{F}_{14}$, when $\Delta>\Delta_{11}$, we get $\bar{F}_{11}<\bar{F}_{13}<\bar{F}_{12}<\bar{F}_{14}$.

In conclusion, we obtain the results in Table 2.

For supplier 1 , the benefit from certification can be denoted as $\pi_{s 1}^{*}\left(\zeta_{1}=\zeta_{2}=\right.$ 1) $-\pi_{s 1}^{*}\left(\zeta_{1}=\zeta_{2}=0\right)=F_{1}(\Delta) \triangleq \frac{\Delta(4+\Delta)(1-\theta)}{4(4-\theta)^{2}}-F$. For supplier 2 , the benefit from certification can be denoted as $\pi_{s 2}^{*}\left(\zeta_{1}=\zeta_{2}=1\right)-\pi_{s 2}^{*}\left(\zeta_{1}=\zeta_{2}=0\right)=F_{2}(\Delta) \triangleq$ $\frac{\Delta(1-\theta)(\Delta+\theta)}{(4-\theta)^{2} \theta}-F$. When $F>\max \left\{\frac{\Delta(4+\Delta)(1-\theta)}{4(4-\theta)^{2}}, \frac{\Delta(1-\theta)(\Delta+\theta)}{(4-\theta)^{2} \theta}\right\}=\frac{\Delta(1-\theta)(\Delta+\theta)}{(4-\theta)^{2} \theta}$ in the 1-1 strategy, two suppliers will fall into the prisoner's dilemma. In Cases (3) (7), two 
suppliers will both certify the product when $F<\bar{F}_{13}$. Since $\bar{F}_{13}-\frac{\Delta(1-\theta)(\Delta+\theta)}{(4-\theta)^{2} \theta}=$ $\frac{\Delta(4(1-\theta) \theta+\Delta(-4+(4-\theta)(2-\theta) \theta))}{4(4-\theta)^{2}(1-\theta) \theta}$, if $\Delta<\frac{4(1-\theta) \theta}{4-(4-\theta)(2-\theta) \theta}$, we get two suppliers will fall in the prisoner's dilemma if they reach $1-1$ equilibrium in Cases (3) $\sim(7)$. Since $\bar{F}_{21}-$ $F_{2}(\Delta)-F=\frac{(1-\theta) \theta}{4(-4+\theta)^{2}}>0$, we get two suppliers will fall in the prisoner's dilemma if they reach 1-1 equilibrium in Cases (8) and (10). In Cases (1) and (2), two suppliers will both certify the product when $F<\bar{F}_{11}$. Since $\bar{F}_{11}-F_{2}(\Delta)-F=$ $\frac{\Delta \theta(2-\Delta-2 \theta)}{4(4-\theta)^{2}(1-\theta)}>0$, we get two suppliers will fall in the prisoner's dilemma if they reach 1-1 equilibrium in Cases (1) and (2). In Case (9), two suppliers will both certify the product when $F<\bar{F}_{33}$. Since $\bar{F}_{33}-F_{2}(\Delta)-F=\frac{(1-\theta)\left(\Delta^{2}(-4+\theta)+4 \theta\right)}{4(4-\theta)^{2} \theta}$, if $\Delta<2 \sqrt{\frac{\theta}{4-\theta}}$, we get two suppliers will fall in the prisoner's dilemma if they reach 1-1 equilibrium in Case (9).

\section{Proof of Proposition 5}

We then consider the condition that $1-\theta<\Delta \leq \min \{2-2 \theta, 1\}$, the retailer will only procure the products from supplier 1 in the certification - no certification scenario. By equating $\pi_{s 2 y y}^{*}$ and $\pi_{s 2 y n}^{*}$, we get the threshold certification cost $\bar{F}_{21}=\frac{(2 \Delta+\theta)^{2}(1-\theta)}{4(4-\theta)^{2} \theta}$; by equating $\pi_{s 2 n y}^{*}$ and $\pi_{s 2 n n}^{*}$, we get $\bar{F}_{12}=$ $\frac{\Delta(2-\theta)(\Delta(2-\theta)+2(1-\theta) \theta)}{4(-4+\theta)^{2}(1-\theta) \theta}$; by equating $\pi_{s 1 y y}^{*}$ and $\pi_{s 1 n y}^{*}$, we get $\bar{F}_{13}=\frac{\Delta(2-\theta)(4-(4+\Delta) \theta)}{4(-4+\theta)^{2}(1-\theta)}$; by equating $\pi_{s 1 y n}^{*}$ and $\pi_{s 1 n n}^{*}$, we get $\bar{F}_{22}=\frac{(1+\Delta)^{2}}{16}-\frac{(1-\theta)}{(4-\theta)^{2}}$.

When $1-\theta<\Delta \leq \min \{2-2 \theta, 1\}$, we get that:

$$
\begin{aligned}
& \bar{F}_{13}-\bar{F}_{22}=\frac{-2 \Delta(1-\theta) \theta^{2}-(1-\theta) \theta(8+\theta)+\Delta^{2}(-16+\theta(16+(-5+\theta) \theta))}{16(4-\theta)^{2}(1-\theta)}<0, \\
& \bar{F}_{21}-\bar{F}_{12}=\frac{\Delta^{2}(4-3 \theta)+2 \Delta(1-\theta) \theta-(1-\theta)^{2} \theta}{4(4-\theta)^{2}(-1+\theta)}<0 \text { and } \frac{\bar{F}_{12}}{\bar{F}_{13}}=\frac{\Delta(2-\theta)+2(1-\theta) \theta}{4 \theta-(4+\Delta) \theta^{2}}>1 .
\end{aligned}
$$

Since $\frac{\bar{F}_{12}}{\bar{F}_{22}}=\frac{4 \Delta(2-\theta)(\Delta(2-\theta)+2(1-\theta) \theta)}{(1+\Delta)^{2}(4-\theta)^{2}(1-\theta) \theta-16 \theta(1-\theta)^{2}}$, we let $F_{11}(\theta, \Delta)=4 \Delta(2-\theta)(\Delta(2-$ $\theta)+2(1-\theta) \theta)-(1+\Delta)^{2}(4-\theta)^{2}(1-\theta) \theta+16 \theta(1-\theta)^{2}, \quad \theta_{21} \approx 0.39$ and satisfies $F_{11}\left(\theta_{21}, \Delta=1-\theta_{21}\right)=0, \theta_{22} \approx 0.5803$ and satisfies $F_{11}\left(\theta_{22}, \Delta=2-\right.$ $\left.2 \theta_{22}\right)=0, F_{11}(\theta, \Delta=1)>0$, when $\theta>\theta_{22}, \bar{F}_{12}<\bar{F}_{22}$, when $\theta<\theta_{21}, \bar{F}_{12}>$ 
$\bar{F}_{22}$, when $\theta_{21}<\theta<\theta_{22}$, there exists $F_{11}\left(\theta, \Delta_{21}\right)=0$ and satisfies $\Delta_{21}=$ $\frac{(1-\theta) \theta(8-(4-\theta) \theta)+2 \sqrt{(4-\theta)(1-\theta) \theta^{2}(12-(4-\theta) \theta(5-2 \theta))}}{16-(4-\theta) \theta(8-(5-\theta) \theta)}$, if $\Delta<\Delta_{21}, \bar{F}_{12}<\bar{F}_{22}$, else, $\bar{F}_{12}>$ $\bar{F}_{22}$.

Since $\quad \bar{F}_{13}-\bar{F}_{21}=\frac{-(1-\theta)^{2}(2 \Delta+\theta)^{2}-\Delta(2-\theta) \theta(-4+(4+\Delta) \theta)}{4(4-\theta)^{2} \theta(1-\theta)}$, we let $F_{12}(\theta, \Delta)=$ $-(1-\theta)^{2}(2 \Delta+\theta)^{2}-\Delta(2-\theta) \theta(-4+(4+\Delta) \theta)$, and satisfies $F_{12}\left(\frac{5-\sqrt{17}}{2}, \Delta=\right.$ $1-\theta)=0, F_{12}\left(\frac{9-\sqrt{17}}{8}, \Delta=2-2 \theta\right)=0$, when $\theta>\frac{9-\sqrt{17}}{8}, \bar{F}_{13}>\bar{F}_{21}$, when $\theta<$ $\frac{5-\sqrt{17}}{2}, \quad \bar{F}_{13}<\bar{F}_{21} \quad$, when $\frac{5-\sqrt{17}}{2}<\theta<\frac{9-\sqrt{17}}{8}$, there exists $\Delta_{22}=$ $\frac{-2(1-\theta) \theta-\sqrt{(4-\theta)(2-\theta)(1-\theta)^{2} \theta^{3}}}{-4+(4-\theta)(2-\theta) \theta}$, if $\Delta<\Delta_{22}, \bar{F}_{13}>\bar{F}_{21}$, else, $\bar{F}_{13}<\bar{F}_{21}$.

Since $\bar{F}_{21}-\bar{F}_{22}=\frac{4(2 \Delta+\theta)^{2}(1-\theta)-(4-\theta)^{2} \theta(1+\Delta)^{2}+16 \theta(1-\theta)}{16(4-\theta)^{2} \theta}$, we let $F_{13}(\theta, \Delta)=$ $4(2 \Delta+\theta)^{2}(1-\theta)-(4-\theta)^{2} \theta(1+\Delta)^{2}+16 \theta(1-\theta), \theta_{23} \approx 0.288$ and satisfies $F_{13}\left(\theta_{23}, \Delta=1-\theta_{23}\right)=0, \theta_{24} \approx 0.336$ and satisfies $F_{13}\left(\theta_{24}, \Delta=1\right)=0$, when $\theta>\theta_{24}, \bar{F}_{21}<\bar{F}_{22}$, when $\theta<\theta_{23}, \bar{F}_{21}>\bar{F}_{22}$, when $\theta_{23}<\theta<\theta_{24}$, there exists $F_{13}\left(\theta, \Delta_{23}\right)=0$ and satisfies $\Delta_{23}=-\frac{8 \theta+\theta^{3}+2 \theta \sqrt{(1-\theta)(32+\theta(20-(8-\theta) \theta))}}{-16+\theta(32-(8-\theta) \theta)}$, if $\Delta<\Delta_{23}$, $\bar{F}_{21}<\bar{F}_{22}$, else, $\bar{F}_{21}>\bar{F}_{22}$.

In conclusion, we obtain the results in Table 3.

We then consider the condition that $2-2 \theta<\Delta \leq 1 \cap \theta>\frac{1}{2}$, thus, when in the certification-no certification scenario, the retailer will only procure the products from supplier 1; when in the no certification-certification scenario, the retailer will only procure the products from supplier 2 .

By equating $\pi_{s 2 y y}^{*}$ and $\pi_{s 2 y n}^{*}$, we get the threshold certification cost $\bar{F}_{21}=$ $\frac{(2 \Delta+\theta)^{2}(1-\theta)}{4(4-\theta)^{2} \theta}$; by equating $\pi_{s 2 n y}^{*}$ and $\pi_{s 2 n n}^{*}$, we get $\bar{F}_{34}=\frac{(\theta+\Delta)^{2}}{16 \theta}-\frac{\theta(1-\theta)}{4(-4+\theta)^{2}}$; by equating $\pi_{s 1 y y}^{*}$ and $\pi_{s 1 n y}^{*}$, we get $\bar{F}_{33}=\frac{(1-\theta)(\Delta+2)^{2}}{4(4-\theta)^{2}}$; by equating $\pi_{s 1 y n}^{*}$ and $\pi_{s 1 n n}^{*}$, we get $\bar{F}_{22}=\frac{(1+\Delta)^{2}}{16}-\frac{1-\theta}{(4-\theta)^{2}}$. Then, we get $\bar{F}_{21}-\bar{F}_{34}=\frac{-\theta}{16(4-\theta)^{2} \theta}\left(8 \theta+\theta^{3}+\right.$ $\left.\Delta^{2}(8+\theta)+2 \Delta\left(8+\theta^{2}\right)\right)<0, \quad \bar{F}_{33}-\bar{F}_{22}=\frac{16-4 \Delta(4+3 \Delta)-24 \theta+4 \Delta^{2} \theta-(1+\Delta)^{2} \theta^{2}}{16(4-\theta)^{2}}<0$. 
Since $\bar{F}_{21}-\bar{F}_{33}=\frac{\left(\Delta^{2}-\theta\right)(4-\theta)(1-\theta)}{4(4-\theta)^{2} \theta}$, thus if $\Delta<\sqrt{\theta}, \bar{F}_{21}<\bar{F}_{33}$; if $\Delta>\sqrt{\theta}, \bar{F}_{21}>$ $\bar{F}_{33} \cdot \bar{F}_{21}-\bar{F}_{22}=\frac{-(1+\Delta)^{2}(4-\theta)^{2} \theta+16(1-\theta) \theta+4(1-\theta)(2 \Delta+\theta)^{2}}{16 \theta(4-\theta)^{2}}<0 \quad, \quad \bar{F}_{34}-\bar{F}_{22}=$ $\frac{(1-\theta)\left(\Delta^{2}(4-\theta)+\theta^{2}\right)}{16 \theta(4-\theta)}>0$. Thus, we get the results in Table 4 .

\section{Proof of Proposition 6}

When two suppliers both certify the product, we get that $\pi_{s 1}^{*}-\pi_{s 2}^{*}=$ $\frac{(1-\theta)\left(-\Delta^{2}+\theta\right)}{4(4-\theta) \theta}$, if $\Delta<\sqrt{\theta}, \pi_{s 1}^{*}>\pi_{s 2}^{*}$; if $\Delta>\sqrt{\theta}, \pi_{s 1}^{*}<\pi_{s 2}^{*}$. When two suppliers do not certify the product, we get that $\pi_{s 1}^{*}-\pi_{s 2}^{*}=\frac{1-\theta}{4(4-\theta)}>0$. To realize $\pi_{s 1}^{*}<\pi_{s 2}^{*}$, the condition $\theta<\frac{3-\sqrt{5}}{2}$ and $\sqrt{\theta}<\Delta<1-\theta$ must be satisfied. We find $\Delta_{11}<\Delta_{12}<$ $\sqrt{\theta}$, but there exists $\theta_{31}$ satisfying $\Delta_{13}\left(\theta_{31}\right)=\sqrt{\theta_{31}}, \theta_{31} \approx 0.263, \Delta_{13}>\sqrt{\theta}$ if $\theta_{31}<\theta<\frac{7-\sqrt{41}}{2}$. Thus, if two suppliers reach $1-1$ equilibrium, supplier 2 may obtain more profits than supplier 1 if $\theta<\frac{7-\sqrt{41}}{2}$ in Cases (3) and (4), and if $\frac{7-\sqrt{41}}{2}<\theta<$ $\frac{5-\sqrt{17}}{2}$ in Case (3). When $\bar{F}_{13}<F<\bar{F}_{12}$ in Cases (2)-(4), two suppliers achieve 0-1 equilibrium, we get $\pi_{s 1}^{*}-\pi_{s 2}^{*}=F-\frac{\Delta^{2}+2 \Delta \theta-\theta(1-\theta)}{4(4-\theta) \theta}$. Since $f_{6}(\Delta)=\frac{\Delta^{2}+2 \Delta \theta-\theta(1-\theta)}{4(4-\theta) \theta}-$ $\bar{F}_{13}=\frac{1}{4(4-\theta)^{2}(1-\theta) \theta}\left((-4+\theta)(1-\theta)^{2} \theta-2 \Delta(1-\theta) \theta^{2}+\Delta^{2}(4-\theta(5-(3-\right.$ $\theta) \theta)$ )), if $f_{6}(\Delta)>0$, we get $\pi_{s 1}^{*}<\pi_{s 2}^{*}$ in a 0-1 equilibrium. $f_{6}\left(\theta_{32}, \Delta=1-\theta_{32}\right)=$ $0, \theta_{32} \approx 0.484$, if $\theta>\theta_{32}, f_{6}(\Delta=1-\theta)<0$, thus, $f_{6}(\Delta)<0 . f_{6}\left(\Delta=\Delta_{11}\right)<0$, $f_{6}\left(\theta_{33}, \Delta=\Delta_{12}\right)=0, \theta_{33} \approx 0.403$, if $\theta>\theta_{33}, f_{6}\left(\Delta=\Delta_{12}\right)>0$, else, $f_{6}(\Delta=$ $\left.\Delta_{12}\right)<0 . f_{6}\left(\theta_{34}, \Delta=\Delta_{13}\right)=0, \theta_{34} \approx 0.243$, if $\theta>\theta_{34}, f_{6}\left(\Delta=\Delta_{13}\right)>0$, else, $f_{6}\left(\Delta=\Delta_{13}\right)<0$. Thus, we get there exists $\theta$ satisfying $\pi_{s 1}^{*}<\pi_{s 2}^{*}$ if $\theta<\frac{7-\sqrt{41}}{2}$ in Cases (3) and (4), $\frac{7-\sqrt{41}}{2}<\theta<\frac{5-\sqrt{17}}{2}$ in Cases (2) and (3) and if $\frac{5-\sqrt{17}}{2}<\theta<\theta_{32}$ in Case (2). When $\bar{F}_{11}<F<\bar{F}_{13}$ in Cases (1)-(3), two suppliers achieve 1-0 equilibrium, we get $\pi_{s 1}^{*}-\pi_{s 2}^{*}=\frac{(1+\Delta)^{2}-\theta}{4(4-\theta)}-F$. Since $f_{7}(\Delta)=\bar{F}_{13}-\frac{(1+\Delta)^{2}-\theta}{4(4-\theta)}=$ $\frac{1}{4(4-\theta)^{2}(-1+\theta)}\left(\Delta^{2}(4-3 \theta)+(4-\theta)(1-\theta)^{2}+2 \Delta(1-\theta) \theta\right)<0$, thus, $\pi_{s 1}^{*}>\pi_{s 2}^{*}$. 


\section{Appendix C. The equilibrium certification strategy.}

Case (1) $\bar{F}_{11}<\bar{F}_{12}<\bar{F}_{13}<\bar{F}_{14}$

If $F \leq \bar{F}_{11}$, supplier 1(2) always chooses certification regardless of the choice of supplier 2(1), thus they will reach the certification-certification Nash equilibrium, to simplify the exposition, we denote the equilibrium as 1 (dominant)-1(dominant); if $\bar{F}_{11}<F \leq \bar{F}_{12}$, supplier 1 always chooses certification regardless of the choice of supplier 2, supplier 2 will choose no certification if supplier 1 chooses certification, thus they will reach the certification-no certification Nash equilibrium, we denote the equilibrium as 1 (dominant)-0; if $\bar{F}_{12}<F \leq \bar{F}_{13}$, they will reach 1 (dominant)-0 (dominant) Nash equilibrium; if $\bar{F}_{13}<F \leq \bar{F}_{14}$, they will reach 1-0(dominant) Nash equilibrium; if $F>\bar{F}_{14}$, they will reach 0(dominant)-0(dominant) Nash equilibrium. Case (2) $\bar{F}_{11}<\bar{F}_{13}<\bar{F}_{12}<\bar{F}_{14}$

If $F \leq \bar{F}_{11}$, they will reach 1 (dominant)-1(dominant) Nash equilibrium; if $\bar{F}_{11}<$ $F \leq \bar{F}_{13}$, they will reach 1(dominant)-0 Nash equilibrium; if $\bar{F}_{13}<F \leq \bar{F}_{12}$, they will reach 1-0 or 0-1 Nash equilibrium; if $\bar{F}_{12}<F \leq \bar{F}_{14}$, they will reach 1-0 (dominant) Nash equilibrium; if $F>\bar{F}_{14}$, they will reach 0 (dominant)-0(dominant) Nash equilibrium.

Case (3) $\bar{F}_{13}<\bar{F}_{11}<\bar{F}_{14}<\bar{F}_{12}$

If $F \leq \bar{F}_{13}$, they will reach 1 (dominant)-1(dominant) Nash equilibrium; if $\bar{F}_{13}<$ $F \leq \bar{F}_{11}$, they will reach 0-1(dominant) Nash equilibrium; if $\bar{F}_{11}<F \leq \bar{F}_{14}$, they will reach 1-0 or 0-1 Nash equilibrium; if $\bar{F}_{14}<F \leq \bar{F}_{12}$, they will reach 0 (dominant)-1 Nash equilibrium; if $F>\bar{F}_{12}$, they will reach 0 (dominant)-0(dominant) Nash equilibrium.

Case (4) $\bar{F}_{13}<\bar{F}_{14}<\bar{F}_{11}<\bar{F}_{12}$

If $F \leq \bar{F}_{13}$, they will reach 1 (dominant)-1(dominant) Nash equilibrium; if $\bar{F}_{13}<$ $F \leq \bar{F}_{14}$, they will reach 0-1(dominant) Nash equilibrium; if $\bar{F}_{14}<F \leq \bar{F}_{11}$, they will reach 0 (dominant)-1(dominant) Nash equilibrium; if $\bar{F}_{11}<F \leq \bar{F}_{12}$, they will reach 0(dominant)-1 Nash equilibrium; if $F>\bar{F}_{12}$, they will reach 0(dominant)-0(dominant) Nash equilibrium. 
Case (5) $\bar{F}_{13}<\bar{F}_{22}<\bar{F}_{21}<\bar{F}_{12}$

If $F \leq \bar{F}_{13}$, they will reach 1 (dominant)-1(dominant) Nash equilibrium; if $\bar{F}_{13}<$ $F \leq \bar{F}_{22}$, they will reach 0-1(dominant) Nash equilibrium; if $\bar{F}_{22}<F \leq \bar{F}_{21}$, they will reach 0 (dominant)-1(dominant) Nash equilibrium; if $\bar{F}_{21}<F \leq \bar{F}_{12}$, they will reach 0 (dominant)-1 Nash equilibrium; if $F>\bar{F}_{12}$, they will reach 0(dominant)-0(dominant) Nash equilibrium.

Case (6) $\bar{F}_{13}<\bar{F}_{21}<\bar{F}_{22}<\bar{F}_{12}$

If $F \leq \bar{F}_{13}$, they will reach 1 (dominant)-1(dominant) Nash equilibrium; if $\bar{F}_{13}<$ $F \leq \bar{F}_{21}$, they will reach 0-1(dominant) Nash equilibrium; if $\bar{F}_{21}<F \leq \bar{F}_{22}$, they will reach 1-0 or 0-1 Nash equilibrium; if $\bar{F}_{22}<F \leq \bar{F}_{12}$, they will reach 0 (dominant)-1 Nash equilibrium; if $F>\bar{F}_{12}$, they will reach 0(dominant)-0(dominant) Nash equilibrium.

Case (7) $\bar{F}_{13}<\bar{F}_{21}<\bar{F}_{12}<\bar{F}_{22}$

If $F \leq \bar{F}_{13}$, they will reach 1 (dominant)-1(dominant) Nash equilibrium; if $\bar{F}_{13}<$ $F \leq \bar{F}_{21}$, they will reach 0-1(dominant) Nash equilibrium; if $\bar{F}_{21}<F \leq \bar{F}_{12}$, they will reach 1-0 or 0-1 Nash equilibrium; if $\bar{F}_{12}<F \leq \bar{F}_{22}$, they will reach 1-0 (dominant) Nash equilibrium; if $F>\bar{F}_{22}$, they will reach 0(dominant)-0(dominant) Nash equilibrium.

Case (8) $\bar{F}_{21}<\bar{F}_{13}<\bar{F}_{12}<\bar{F}_{22}$

If $F \leq \bar{F}_{21}$, they will reach 1(dominant)-1(dominant) Nash equilibrium; if $\bar{F}_{21}<F \leq \bar{F}_{13}$, they will reach 1 (dominant)-0 Nash equilibrium; if $\bar{F}_{13}<F \leq \bar{F}_{12}$, they will reach 1-0 or 0-1 Nash equilibrium; if $\bar{F}_{12}<F \leq \bar{F}_{22}$, they will reach 1-0 (dominant) Nash equilibrium; if $F>\bar{F}_{22}$, they will reach 0(dominant)-0(dominant) Nash equilibrium.

Case (9) $\bar{F}_{33}<\bar{F}_{21}<\bar{F}_{22}<\bar{F}_{34}$

If $F \leq \bar{F}_{33}$, they will reach 1(dominant)-1(dominant) Nash equilibrium; if $\bar{F}_{33}<F \leq \bar{F}_{21}$, they will reach 0-1(dominant) Nash equilibrium; if $\bar{F}_{21}<F \leq \bar{F}_{22}$, they will reach 1-0 or 0-1 Nash equilibrium; if $\bar{F}_{22}<F \leq \bar{F}_{34}$, they will reach 0 (dominant)-1 Nash equilibrium; if $F>\bar{F}_{34}$, they will reach 0(dominant)-0(dominant) 
Nash equilibrium.

Case (10) $\bar{F}_{21}<\bar{F}_{33}<\bar{F}_{22}<\bar{F}_{34}$

If $F \leq \bar{F}_{21}$, they will reach 1(dominant)-1(dominant) Nash equilibrium; if $\bar{F}_{21}<F \leq \bar{F}_{33}$, they will reach 1 (dominant)-0 Nash equilibrium; if $\bar{F}_{33}<F \leq \bar{F}_{22}$, they will reach 1-0 or 0-1 Nash equilibrium; if $\bar{F}_{22}<F \leq \bar{F}_{34}$, they will reach 0 (dominant)-1 Nash equilibrium; if $F>\bar{F}_{34}$, they will reach 0(dominant)-0(dominant) Nash equilibrium.

Each of above cases can be divided into 5 parts with the increase of $F$, we denote five parts in each case as the first part, second part fifth part, respectively, which show that two suppliers will reach 1-1 equilibrium in the first part, and reach 0-0 equilibrium in the fifth part.

\section{Appendix D. The certification and pricing decisions considering}

\section{production cost.}

We incorporate the production cost into the model, and analyze the certification and pricing decisions in a simultaneous game. We mainly focus on the condition when the retailer will always procure two products regardless of their certification strategy.

When $\frac{p_{2}-\zeta_{2} \Delta}{p_{1}-\zeta_{1} \Delta} \leq \theta \leq 1-p_{1}+p_{2}+\left(\zeta_{1}-\zeta_{2}\right) \Delta$, we get the optimal pricing decisions,

$$
\begin{aligned}
& m_{1}^{*}=\frac{1}{2}\left(1-c+\Delta \zeta_{1}\right), \\
& m_{2}^{*}=\frac{1}{2}\left(\theta+\Delta \zeta_{2}-c\right) \\
& w_{1}^{*}=\frac{2+7 c-(2+c) \theta+\Delta(2-\theta) \zeta_{1}-\Delta \zeta_{2}}{2(4-\theta)}, \\
& w_{2}^{*}=\frac{6 c+(1-\theta) \theta-\Delta \theta \zeta_{1}+\Delta(2-\theta) \zeta_{2}}{2(4-\theta)}, \\
& p_{1}^{*}=\frac{6+3 c-3 \theta+2 \Delta(3-\theta) \zeta_{1}-\Delta \zeta_{2}}{2(4-\theta)}, \\
& p_{2}^{*}=\frac{c(2+\theta)+\theta(5-2 \theta)-\Delta \theta \zeta_{1}+2 \Delta(3-\theta) \zeta_{2}}{2(4-\theta)}, \\
& \pi_{s 1}^{*}=\frac{\left((2-c)(1-\theta)+\Delta(2-\theta) \zeta_{1}-\Delta \zeta_{2}\right)^{2}}{4(4-\theta)^{2}(1-\theta)}-\zeta_{1} F,
\end{aligned}
$$


$\pi_{s 2}^{*}=\frac{\left((2 c-\theta)(1-\theta)+\Delta \theta \zeta_{1}-\Delta(2-\theta) \zeta_{2}\right)^{2}}{4(4-\theta)^{2}(1-\theta) \theta}-\zeta_{2} F$,

$\pi_{r}^{*}=\frac{1}{4(4-\theta)(1-\theta) \theta}\left((1-\theta)\left(\left(c^{2}+\theta\right)(2+\theta)-6 c \theta\right)+\Delta^{2}(2-\theta) \theta \zeta_{1}^{2}+2 \Delta(1-\right.$

$\left.\theta)(\theta-2 c) \zeta_{2}+\Delta^{2}(2-\theta) \zeta_{2}^{2}+2 \Delta \theta \zeta_{1}\left((2-c)(1-\theta)-\Delta \zeta_{2}\right)\right)$.

After substituting $p_{1}^{*}$ and $p_{2}^{*}$ into the constraint $\frac{p_{2}-\zeta_{2} \Delta}{p_{1}-\zeta_{1} \Delta} \leq \theta \leq 1-p_{1}+p_{2}+$ $\left(\zeta_{1}-\zeta_{2}\right) \Delta$, we get the following conditions under which the retailer will simultaneously procure two products.

In scenario 1, if $c \leq \frac{2 \Delta+\theta}{2}$, the retailer will procure two products simultaneously, otherwise, he will only procure product 1 ; in scenario II, if $c \leq \frac{\theta(1-\Delta-\theta)}{2(1-\theta)}$, the retailer will procure two products simultaneously, otherwise, he will only procure product 1 ; in scenario III, if $\Delta \geq 1-\theta$ and $c \leq \frac{2(2-\Delta-2 \theta)}{2(1-\theta)}$, the retailer will procure two products simultaneously, otherwise, he will only procure product 2; if $\Delta \leq 1-\theta$ and $c \leq \frac{2 \Delta+\theta-\theta(\Delta+\theta)}{2(1-\theta)}$, the retailer will procure two products simultaneously, otherwise, he will only procure product 1 ; in scenario IV, if $c \leq \frac{\theta}{2}$, the retailer will procure two products simultaneously, otherwise, he will only procure product 1 . We mainly focus on the condition of $\Delta \leq 1-\theta-\frac{2(1-\theta) c}{\theta}$, and we get $c \leq \frac{\theta}{2}$ according to $1-\theta-$ $\frac{2(1-\theta) c}{\theta} \geq 0$

For supplier 2, given that supplier 1 adopts certification, supplier 2 adopts certification if $F \leq \bar{F}_{41}=\frac{\Delta(2-\theta)(\Delta(2-3 \theta)+(2 \theta-4 c)(1-\theta))}{4(4-\theta)^{2}(1-\theta) \theta}$, otherwise no certification; given that supplier 1 adopts no certification, supplier 2 adopts certification if $F \leq$ $\bar{F}_{42}=\frac{\Delta(2-\theta)(\Delta(2-\theta)+(2 \theta-4 c)(1-\theta))}{4(4-\theta)^{2}(1-\theta) \theta}$, otherwise no certification. For supplier 1, given that supplier 2 adopts certification, supplier 1 adopts certification if $F \leq \bar{F}_{43}=$ $\frac{\Delta(2-\theta)(4-2 c(1-\theta)-(4+\Delta) \theta)}{4(-4+\theta)^{2}(1-\theta)}$, otherwise no certification; given that supplier 2 adopts no certification, supplier 1 adopts certification if

$F \leq \bar{F}_{44}=\frac{\Delta(2-\theta)(2(2+\Delta)-2 c(1-\theta)-(4+\Delta) \theta)}{4(4-\theta)^{2}(1-\theta)}$, otherwise no certification. 
$\frac{\bar{F}_{41}}{\bar{F}_{42}}=\frac{\Delta(2-3 \theta)+(2 \theta-4 c)(1-\theta)}{\Delta(2-\theta)+(2 \theta-4 c)(1-\theta)}<1, \quad \frac{\bar{F}_{43}}{\bar{F}_{44}}=\frac{4-2 c(1-\theta)-(4+\Delta) \theta}{2(2+\Delta)-2 c(1-\theta)-(4+\Delta) \theta}<1$. Since $\frac{\bar{F}_{41}}{\bar{F}_{44}}=$ $\frac{(\Delta(2-3 \theta)+(2 \theta-4 c)(1-\theta))}{\theta(2(2+\Delta)-2 c(1-\theta)-(4+\Delta) \theta)}$, we let $\quad F_{41}(\theta, \Delta)=\Delta(2-3 \theta)+(2 \theta-4 c)(1-\theta)-$ $\theta(2(2+\Delta)-2 c(1-\theta)-(4+\Delta) \theta)$. Since $\frac{\bar{F}_{42}}{\bar{F}_{43}}=\frac{\Delta(2-\theta)(\Delta(2-\theta)+(2 \theta-4 c)(1-\theta))}{4(4-\theta)^{2}(1-\theta) \theta}$, we let $\quad F_{42}(\theta, \Delta)=\Delta(2-\theta)+(2 \theta-4 c)(1-\theta)-\theta(4-2 c(1-\theta)-(4+\Delta) \theta)$. Since $\quad \frac{\bar{F}_{41}}{\bar{F}_{43}}=\frac{(\Delta(2-3 \theta)+(2 \theta-4 c)(1-\theta))}{\theta(4-2 c(1-\theta)-(4+\Delta) \theta)}$ and $\quad \frac{\bar{F}_{42}}{\bar{F}_{44}}=\frac{(\Delta(2-\theta)+(2 \theta-4 c)(1-\theta))}{\theta(2(2+\Delta)-2 c(1-\theta)-(4+\Delta) \theta)}$, we let $F_{43}(\theta, \Delta)=\Delta(2-3 \theta)+(2 \theta-4 c)(1-\theta)$, we let $F_{41}\left(\theta, 1-\theta-\frac{2(1-\theta) c_{1}}{\theta}\right)=0$ and $\quad c_{1}=\frac{\theta\left(\theta^{2}-7 \theta+2\right)}{4-6 \theta} ; \quad F_{42}\left(\theta, 1-\theta-\frac{2(1-\theta) c_{2}}{\theta}\right)=0 \quad$ and $\quad c_{2}=\frac{\theta(2-\theta)(1-\theta)}{2(2+\theta)} ;$ $F_{43}\left(\theta, 1-\theta-\frac{2(1-\theta) c_{3}}{\theta}\right)=0$ and $c_{3}=\frac{\theta\left(\theta^{2}-5 \theta+2\right)}{2(2-\theta)} ; \quad F_{41}\left(\theta, \Delta_{41}\right)=0$ and $\Delta_{41}=$ $\frac{2(c(2-\theta)+\theta)(1-\theta)}{2-(1-\theta) \theta} ; F_{42}\left(\theta, \Delta_{42}\right)=0$ and $\Delta_{42}=2 c+\frac{2 \theta}{2-\theta} ; F_{43}\left(\theta, \Delta_{43}\right)=0$ and $\Delta_{43}=$ $\frac{2(c(2-\theta)+\theta)(1-\theta)}{2-(5-\theta) \theta}, \Delta_{41}<\Delta_{42}<\Delta_{43}$, then, we get Table 5 .

Table 5. The organic certification strategy when $\Delta \leq 1-\theta-\frac{2(1-\theta) c}{\theta}$.

\begin{tabular}{|c|c|c|c|}
\hline$\theta$ & C & $\Delta$ & Case \\
\hline \multirow{12}{*}{$\theta<\frac{2}{3}$} & \multirow[t]{3}{*}{$c<c_{1}$} & $\Delta<\Delta_{41}$ & $(11)$ \\
\hline & & $\Delta_{41}<\Delta<\Delta_{42}$ & $(12)$ \\
\hline & & $\Delta>\Delta_{42}$ & (13) \\
\hline & \multirow[t]{4}{*}{$c_{1}<c<c_{3}$} & $\Delta<\Delta_{41}$ & $(11)$ \\
\hline & & $\Delta_{41}<\Delta<\Delta_{42}$ & $(12)$ \\
\hline & & $\Delta_{42}<\Delta<\Delta_{43}$ & $(13)$ \\
\hline & & $\Delta>\Delta_{43}$ & $(14)$ \\
\hline & \multirow[t]{3}{*}{$c_{3}<c<c_{2}$} & $\Delta<\Delta_{41}$ & $(11)$ \\
\hline & & $\Delta_{41}<\Delta<\Delta_{43}$ & $(12)$ \\
\hline & & $\Delta>\Delta_{43}$ & (14) \\
\hline & \multirow{2}{*}{$c_{2}<c<\frac{\theta}{2}$} & $\Delta<\Delta_{43}$ & $(11)$ \\
\hline & & $\Delta>\Delta_{43}$ & (14) \\
\hline \multirow{6}{*}{$\theta>\frac{2}{3}$} & \multirow[t]{3}{*}{$c<c_{3}$} & $\Delta<\Delta_{41}$ & $(11)$ \\
\hline & & $\Delta_{41}<\Delta<\Delta_{42}$ & $(12)$ \\
\hline & & $\Delta>\Delta_{42}$ & (13) \\
\hline & \multirow[t]{2}{*}{$c_{3}<c<c_{2}$} & $\Delta<\Delta_{41}$ & $(11)$ \\
\hline & & $\Delta>\Delta_{41}$ & $(12)$ \\
\hline & $c_{2}<c<\frac{\theta}{2}$ & & (11) \\
\hline
\end{tabular}

(11) $\bar{F}_{41}<\bar{F}_{42}<\bar{F}_{43}<\bar{F}_{44}$, the certification strategy here is similar to that in Case 
(1); (12) $\bar{F}_{41}<\bar{F}_{43}<\bar{F}_{42}<\bar{F}_{44}$, the certification strategy here is similar to that in

Case (2); (13) $\bar{F}_{43}<\bar{F}_{41}<\bar{F}_{44}<\bar{F}_{12}$, the certification strategy here is similar to that in Case (3); (14) $\bar{F}_{13}<\bar{F}_{14}<\bar{F}_{11}<\bar{F}_{12}$, the certification strategy here is similar to that in Case (4).

\section{References}

Ahearn, M. C., Armbruster, W., \& Young, R. (2016). Big Data’s Potential to Improve Food Supply Chain Environmental Sustainability and Food Safety. International Food and Agribusiness Management Review, 19, 155-163.

Anselmsson, J., VestmanBondesson, N., \& Johansson, U. (2014). Brand image and customers' willingness to pay a price premium for food brands. Journal of Product \& Brand Management, 23(2), 90-102.

Assefa, T. T., Kuiper, W. E., \&Meuwissen, M. P. (2014). The effect of farmer market power on the degree of farm retail price transmission: a simulation model with an application to the Dutch ware potato supply chain. Agribusiness, 30(4), 424-437.

Assunção, M. D., Calheiros, R. N., Bianchi, S., Netto, M. A., \&Buyya, R. (2015). Big Data computing and clouds: Trends and future directions. Journal of Parallel and Distributed Computing, 79, 3-15.

Baltas, G. (2004). A model for multiple brand choice. European Journal of Operational Research, 154(1), 144-149.

Barbosa, R. M., Batista, B. L., Varrique, R. M., Coelho, V. A., Campiglia, A. D., \&Barbosa Jr, F. (2014). The use of advanced chemometric techniques and trace element levels for controlling the authenticity of organic coffee. Food Research International, 61, 246-251.

Barbosa, R. M., de Paula, E. S., Paulelli, A. C., Moore, A. F., Souza, J. M. O., Batista, B. L., ... \& Barbosa Jr, F. (2016). Recognition of organic rice samples based on trace elements and support vector machines. Journal of Food Composition and Analysis, 45, 95-100.

Barrett, H. R., Browne, A. W., Harris, P. J. C., \&Cadoret, K. (2002). Organic certification and the UK market: organic imports from developing countries. 
Food policy, 27(4), 301-318.

Bauer, H. H., Heinrich, D., \& Schäfer, D. B. (2013). The effects of organic labels on global,local, and private brands: More hype than substance? Journal of Business Research, 66(8), 1035-1043.

Beuchelt, T. D., \& Zeller, M. (2011). Profits and poverty: Certification’s troubled link for Nicaragua's organic and fair trade coffee producers. Ecological Economics, 70(7), 1316-1324.

Blackburn, J., \& Scudder, G. (2009). Supply chain strategies for perishable products: the case of fresh produce. Production and Operations Management, 18(2), 129-137.

Cai, X., Chen, J., Xiao, Y., \& Xu, X. (2010). Optimization and coordination of fresh product supply chains with freshness-keeping effort. Production and Operations management, 19(3), 261-278.

Cai, X., Chen, J., Xiao, Y., Xu, X., \& Yu, G. (2013). Fresh-product supply chain management with logistics outsourcing. Omega, 41(4), 752-765.

Chen, M. F. (2007). Consumer attitudes and purchase intentions in relation to organic foods in Taiwan: Moderating effects of food-related personality traits. Food Quality and Preference, 18(7), 1008-1021.

Chen, M., Mao, S., \& Liu, Y. (2014). Big data: A survey. Mobile networks and applications, 19(2), 171-209.

Chiang, W. Y. K., Chhajed, D., \& Hess, J. D. (2003). Direct marketing, indirect profits: A strategic analysis of dual-channel supply-chain design. Management science, 49(1), $1-20$.

Clark, P., \& Martínez, L. (2016). Local alternatives to private agricultural certification in Ecuador: Broadening access to 'new markets' ?. Journal of Rural Studies, 45, 292-302.

Cui, L., \& Huang, Y. (2018). Exploring the schemes for green climate fund financing: international lessons. World Development, 101, 173-187.

Cui, L., \& Song, M. (2019). Economic evaluation of the Belt and Road Initiative from 
an unimpeded trade perspective. International Journal of Logistics Research and Applications, 22(1), 25-46.

Dabbert, S., Lippert, C., \& Zorn, A. (2014). Introduction to the special section on organic certification systems: Policy issues and research topics. Food Policy, 49, 425-428.

De Magistris, T., \&Gracia, A. (2008). The decision to buy organic food products in Southern Italy. British Food Journal, 110(9), 929-947.

Ellison, B., Duff, B. R., Wang, Z., \& White, T. B. (2016). Putting the organic label in context: Examining the interactions between the organic label, product type, and retail outlet. Food Quality and Preference, 49, 140-150.

Ertek, G., \& Griffin, P. M. (2002). Supplier-and buyer-driven channels in a two-stage supply chain. IIE transactions, 34(8), 691-700.

Feng, D. , Chen, Q. , Song, M. , \& Cui, L. (2019). Relationship between the degree of internationalization and performance in manufacturing enterprises of the yangtze river delta region. Emerging Markets Finance and Trade, 55(1), 1-17.

Filippini, R., De Noni, I., Corsi, S., Spigarolo, R., \&Bocchi, S. (2018). Sustainable school food procurement: What factors do affect the introduction and the increase of organic food?.Food Policy, 76, 109-119.

Goetzke, B., Nitzko, S., \& Spiller, A. (2014). Consumption of organic and functional food. A matter of well-being and health?. Appetite, 77, 96-105.

Hazell, P., Poulton, C., Wiggins, S., \&Dorward, A. (2010). The future of small farms: trajectories and policy priorities. World Development, 38(10), 1349-1361.

Howlett, E. A., Burton, S., Bates, K., \& Huggins, K. (2009). Coming to a restaurant near you? Potential consumer responses to nutrition information disclosure on menus. Journal of Consumer Research, 36(3), 494-503.

Hsu, S. Y., Chang, C. C., \& Lin, T. T. (2016). An analysis of purchase intentions toward organic food on health consciousness and food safety with/under structural equation modeling. British Food Journal, 118(1), 200-216.

Janssen, M., \& Hamm, U. (2012). Product labelling in the market for organic food: 
Consumer preferences and willingness-to-pay for different organic certification logos. Food Quality and Preference, 25(1), 9-22.

Jing, B. (2016). Behavior-based pricing, production efficiency, and quality differentiation. Management Science, 63(7), 2365-2376.

Karaer, Ö., \&Erhun, F. (2015). Quality and entry deterrence. European Journal of Operational Research, 240(1), 292-303.

Klonsky, K., \& Tourte, L. (1998). Organic agricultural production in the United States: Debates and directions. American Journal of Agricultural Economics, 80(5), 1119-1124.

Krishna, A. (1992). The normative impact of consumer price expectations for multiple brands on consumer purchase behavior. Marketing Science, 11(3), 266-286.

Lee, W. C. J., Shimizu, M., Kniffin, K. M., \&Wansink, B. (2013). You taste what you see: Do organic labels bias taste perceptions?.Food Quality and Preference, 29(1), 33-39.

Luo, Z., Chen, X., \& Wang, X. (2016). The role of co-opetition in low carbon manufacturing. European Journal of Operational Research, 253(2), 392-403.

Luo, Z., Chen, X., Chen, J., \& Wang, X. (2017). Optimal pricing policies for differentiated brands under different supply chain power structures. European Journal of Operational Research, 259(2), 437-451.

Marotta, G., Simeone, M., \&Nazzaro, C. (2014). Product reformulation in the food system to improve food safety. Evaluation of policy interventions. Appetite, 74, 107-115.

Matsubayashi, N. (2007). Price and quality competition: the effect of differentiation and vertical integration. European Journal of Operational Research, 180(2), 907-921.

Matsubayashi, N., \& Yamada, Y. (2008). A note on price and quality competition between asymmetric firms. European Journal of Operational Research, 187(2), 571-581.

Michaelidou, N., \& Hassan, L. M. (2008). The role of health consciousness, food 
safety concern and ethical identity on attitudes and intentions towards organic food. International Journal of Consumer Studies, 32(2), 163-170.

Motta, M. (1993). Endogenous quality choice: price vs. quantity competition. The Journal of Industrial Economics, 41(2), 113-131.

Ozinci, Y., Perlman, Y., \&Westrich, S. (2017). Competition between organic and conventional products with different utilities and shelf lives. International Journal of Production Economics, 191, 74-84.

Parrot, N., Olesen, J., \&Høgh-Jensen, H. (2007). Certified and noncertified organic farming in the developing world. In N. Halberg, H. Alrøe, M. Knudsen, \& E. Kristensen (Eds.), Global development of organic agriculture: Challenges and promises (pp. 153-180). Wallingford, Oxfordshire, UK: CAB International.

Perlman, Y., Ozinci, Y., \& Westrich, S. (2019). Pricing decisions in a dual supply chain of organic and conventional agricultural products. Annals of Operations Research, 1-16.

Pollard, S., Namazi, H., \& Khaksar, R. (2019). Big data applications in food safety and quality. In L. Melton, F. Shahidi, \& P. Varelis (Eds.), Encyclopedia of food chemistry (pp. 356-363). Oxford: Academic Press.

Popa, M. E., Mitelut, A. C., Popa, E. E., Stan, A., \& Popa, V. I. (2018). Organic foods contribution to nutritional quality and value. Trends in Food Science \& Technology. https://doi.org/10.1016/j.tifs.2018.01.003.

Sazvar, Z., Rahmani, M., \& Govindan, K. (2018). A sustainable supply chain for organic, conventional agro-food products: The role of demand substitution, climate change and public health. Journal of cleaner production, 194, 564-583.

Schifferstein, H. N., \&Ophuis, P. A. O. (1998). Health-related determinants of organic food consumption in the Netherlands. Food Quality and Preference, 9(3), 119-133.

Sjostrom, T., Corsi, A. M., Driesener, C., \&Chrysochou, P. (2014). Are food brands that carry light claims different?.Journal of Brand Management, 21(4), 325-341.

Snider, A., Gutiérrez, I., Sibelet, N., \& Faure, G. (2017). Small farmer cooperatives 
and voluntary coffee certifications: Rewarding progressive farmers of engendering widespread change in Costa Rica?.Food Policy, 69, 231-242.

Teng, L., Laroche, M., \& Zhu, H. (2007). The effects of multiple-ads and multiple-brands on consumer attitude and purchase behavior. Journal of Consumer Marketing, 24(1), 27-35 (9).

Vega-Zamora, M., Torres-Ruiz, F. J., Murgado-Armenteros, E. M., \&Parras-Rosa, M.(2014). Organic as a heuristic cue: What Spanish consumers mean by organic foods.Psychology \& Marketing, 31(5), 349-359.

Veldstra, M. D., Alexander, C. E., \& Marshall, M. I. (2014). To certify or not to certify? Separating the organic production and certification decisions. Food Policy, 49, 429-436.

Wang, C., \& Chen, X. (2017). Option pricing and coordination in the fresh produce supply chain with portfolio contracts. Annals of Operations Research, 248(1-2), 471-491.

Wang, S., Hu, Q., \& Liu, W. (2017). Price and quality-based competition and channel structure with consumer loyalty. European Journal of Operational Research, 262(2), 563-574.

Wu, L., Deng, S., \& Jiang, X. (2018). Sampling and pricing strategy under competition. Omega, 80, 192-208.

Xie, J., Gao, Z., Swisher, M., \& Zhao, X. (2016). Consumers’ preferences for fresh broccolis: interactive effects between country of origin and organic labels. Agricultural Economics, 47(2), 181-191.

Zhou, Y. (2018). The role of green customers under competition: A mixed blessing?.Journal of Cleaner Production, 170, 857-866. 